\title{
Intrusión dental
} con microimplantes 


\title{
Sebastian Di Martino
}

\author{
Dr. en Odontología UDELAR
}

Especialista en Ortopedia y Ortodoncia DF IUCEDDU

email : seba061188@gmail.com

DOI $10.52887 /$ RUOO/v4n2.1

\section{RESUMEN}

La intrusión dental ha sido un gran desafío a lo largo de la historia de los tratamientos ortodóncicos. La dificultad para encontrar un punto de anclaje sobre el cual poder ejercer fuerzas intrusivas controladas sobre las piezas dentales mediante elementos elásticos ha llevado a los ortodoncistas a buscar diversas posibilidades con éxito dispar. Los elementos de anclaje extraoral utilizados hasta entonces se veían limitados, en muchas oportunidades, ya sea por el disconfort que generaban en el paciente como por la falta de colaboración del mismo cuando así lo requiriera el tratamiento. En la terapéutica intraoral las técnicas utilizadas no garantizaban la ausencia de movimientos parásitos en otras piezas dentales y en algunos casos se veían limitadas cuando el movimiento intrusivo deseado era de gran magnitud.

Los microimplantes han abierto las puertas a un nuevo universo de posibilidades de intrusión dental gracias a su gran versatilidad. La incorporación de un elemento que supere en anclaje a todos los elementos intraorales utilizados hasta el momento, que tenga la capacidad de utilizarse sin generar efectos parásitos, que tenga la posibilidad de ser colocado de manera sencilla en casi cualquier sector de la cavidad bucal donde exista tejido óseo

DOI 10.52887/RUOO/v4n2.7 RUOO 2021 Vol 4 N01 jul-dic2021 3-38 
subyacente, permiten ampliar de manera significativa nuestras posibilidades de éxito en el tratamiento. Ésto sumado a que su tamaño reducido mejora la experiencia del paciente, generando una mayor aceptación hacia el tratamiento y compromiso con el mismo.

En éste capítulo desarrollaremos los casos más frecuentes en los que se hace necesaria la intrusión asistida por medio de microimplantes, cómo es el terreno sobre el cual trabajamos, cómo se comporta ese terreno en los diferentes pacientes según sus características, posibilidades de anclaje, el control de las fuerzas a utilizar en cada caso, las posibles variables que nos podemos encontrar durante el tratamiento, cómo corregir desajustes propios de la mecánica sobre la marcha, todo lo que el profesional debe manejar para poder decidir la mejor opción para cada tratamiento en específico.

\section{SUMMARY}

The dental intrusion has been always a challenge thoughout the history of the orthodontic treatments. The difficulty in finding an anchorage point on which it could be set controlled intrusive forces onto the dental peces by means of elastic elements has taken to the orthodontists to look for varios possibilities with not the same success.

The extraoral anchorage elements usted till then were limited, in many opportunities, by the disconfort they produced in the patient or by their lack of colaboration when the treatment requiered it. In the intraoral treatment it did not guarantee the lack of parasite movements in other teeth and sometimes the intrusion Washington limited when the desired movement was of a great sale.

The microscrews have opened the doors of a new universe of possibilities in the dental intrusion thanks to its versatility. The incorporation of an element which exceed the anchorage of every intraoral element used till now, which has the capacity of being used without generating the parasite effect, that has the ability of being placed in a simple way in almost every place in the mouth where exists bone below, allows open in a significative way the our possibilities in the success in our treatments. This, in addition to its reduced size improves the experience of the patient, generating a mayor approval to the treatment and compromise with it.

In this chapter we will develop the most frequent cases in which it is necessary the assisted intrusion by means of microscrews, how is the field in which we are working, how is the behaviour of that field in the different patients with its own characteristics, anchorage possibilities, the control of the forces to use in each case, the possible varities we can find during the treatment, how to correct the mismatches on the way that can appear from the technique itself, all that the proffesional should handle to be able to decide the best option for each specific treatment 
PALABRAS CLAVE: microimplantes, intrusión, plano oclusal, sobremordida, mordida abierta, fuerzas, nivelación.

KEY WORDS : Microscrews, intrusion, oclusal plate, deep bite, open bite, forces, levelling

\section{BASES BIOLÓGICAS}

Las piezas dentales se encuentran relacionadas con el tejido óseo por medio del ligamento periodontal. Este ligamento conecta el cemento radicular con la cortical del hueso alveolar. Ésta conexión es la responsable de transmitir las fuerzas aplicadas a las piezas dentales hacia el tejido óseo generando zonas de presión y de tensión hacia el mismo. Las primeras, si se encuentran dentro de los límites biológicos que permitan la correcta irrigación de la zona, se traducen en forma de reabsorción ósea, gracias a la intervención de los osteoclastos. Si las fuerzas aplicadas superan dichos límites se verá impedida la correcta irrigación y proliferación osteoclástica generándose una zona de hialinización que impedirá el movimiento dental inmediato. Las zonas de tensión, por el contrario, se traducen en aposición ósea, gracias a la acción de los osteoblastos en la zona. Gracias a esta interacción de zonas de presión/reabsorción y tensión/apsosición transmitidas por el ligamento periodontal, se genera el movimiento dental. ${ }^{7}$

El ligamento periodontal está compuesto de múltiples fibras colágenas, elásticas y oxitalánicas junto con los componentes nervioso y vascular, que se disponen en diferentes direcciones dando lugar a 5 grupos distintos (Figura 29):

- Grupo de la cresta alveolar (ascendentes): se extienden desde el área cervical del diente (cuello) hacia la cresta alveolar. Su dirección por lo tanto es ápico-coronario desde el cemento radicular hacia la cresta alveolar. Por esta disposición de las fibras, su función principal es evitar la extrusión dental.

- Grupo horizontal: son las fibras que se dirigen horizontalmente desde el diente al hueso alveolar. Su función es evitar los movimientos de vaivén.

- Grupo oblícuo (descendentes): son las fibras que se extienden oblicuamente desde el cemento hacia el hueso alveolar en dirección corono-apical. Este grupo contiene el mayor porcentaje de fibras del ligamento periodontal y su principal función es evitar la intrusión dental durante la masticación.

DOI 10.52887/RUOO/v4n2.7 RUOO 2021 Vol 4 No1 jul-dic2021 3-38 
- Grupo apical: son las fibras que van desde el ápice del diente al hueso alveolar. Su principal función es la protección del paquete vásculonervioso.

- Grupo interradicular: son las fibras que se encuentran entre las raíces de los dientes multirradiculares.

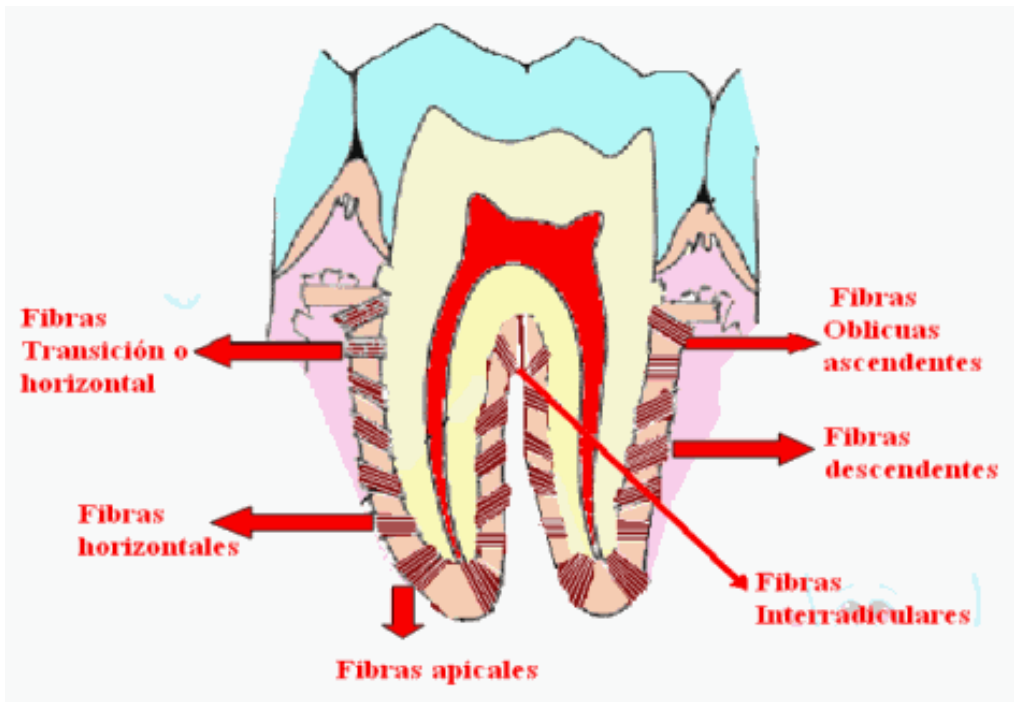

Figura 29: Composición del ligamento periodontal.

La fuerza a aplicar varía de acuerdo a la superficie radicular, con su respectivo ligamento periodontal, que se opone al movimiento de la pieza o sector a intruir. Si nos encontramos con un paciente periodontal, habrá que tenerlo en cuenta a la hora de aplicar las fuerzas, las cuales deberán ser de menor magnitud, manteniendo una relación con el porcentaje y el tipo de pérdida ósea. En casos de pérdida ósea avanzada, si el pronóstico de las piezas es reservado, se deberá poner en la balanza la relación-costo beneficio del tratamiento. ${ }^{7}$

En el sector anterior, el grupo incisivo cuenta con una superficie radicular pequeña por lo que las fuerzas deben ser menores. En cambio, el sector posterior a nivel de molares requiere la aplicación de una fuerza mayor. La zona póstero-superior cuenta con mayor superficie radicular que la inferior, sin embargo, el maxilar inferior en esa zona posee una gran cantidad de hueso compacto (no así en el superior, en el cual, exceptuando la cresta cigomática, predomina el esponjoso), lo que determina que la intrusión póstero-inferior sea más dificultosa y requiera un movimiento previo de torque positivo para alejar las raíces de la cortical vestibular y ubicarlas en la esponjosa. ${ }^{7}$

Las siguientes imágenes del libro "Tratamiento ortodóncico con Arco Recto" de J. Gregoret (Figuras 30 y 31) muestran la cantidad de superficie radicular que se opone a los distintos movimientos: ${ }^{6}$ 


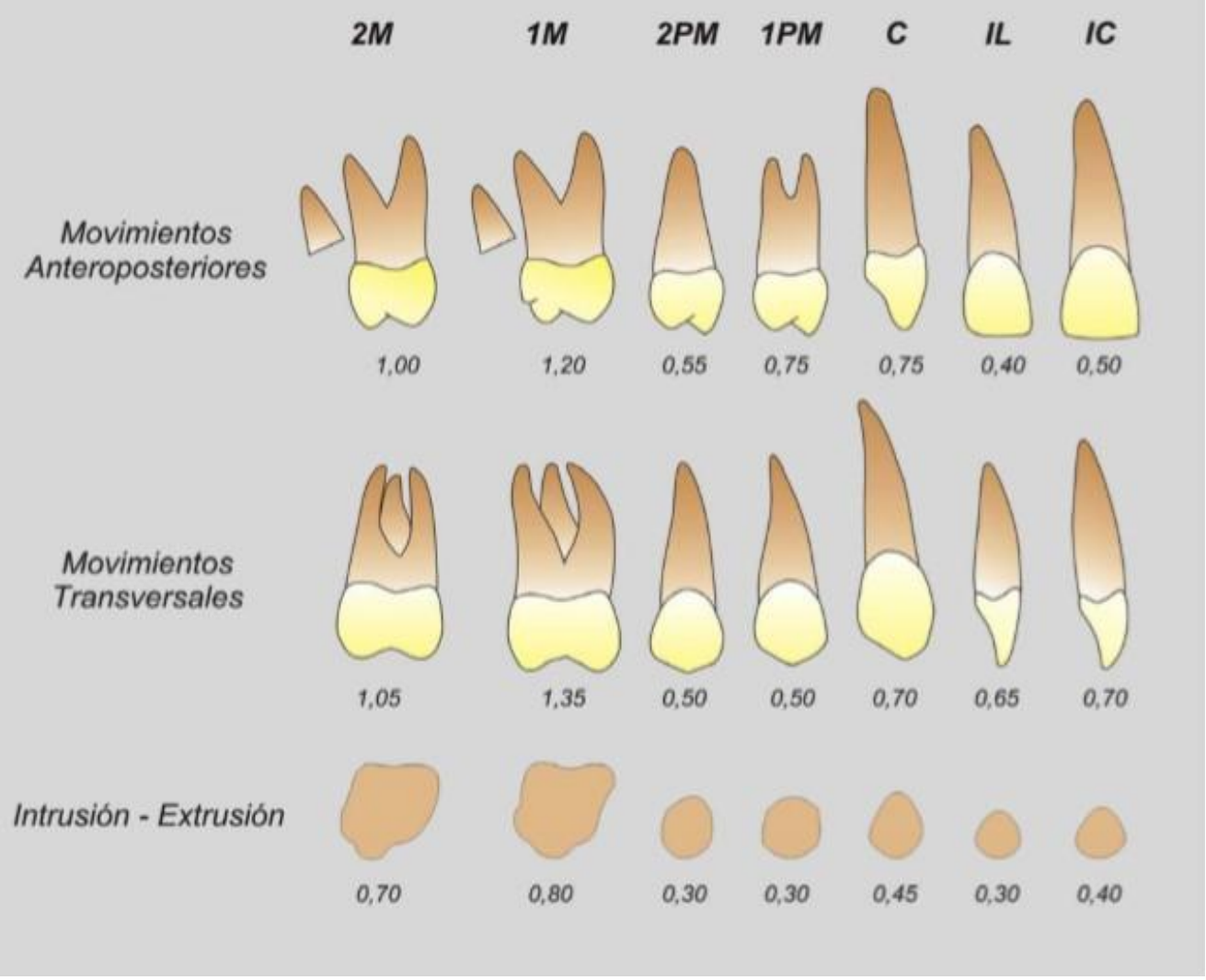

Figura 30: Superficies radiculares que se oponen al movimiento en el maxilar superior.

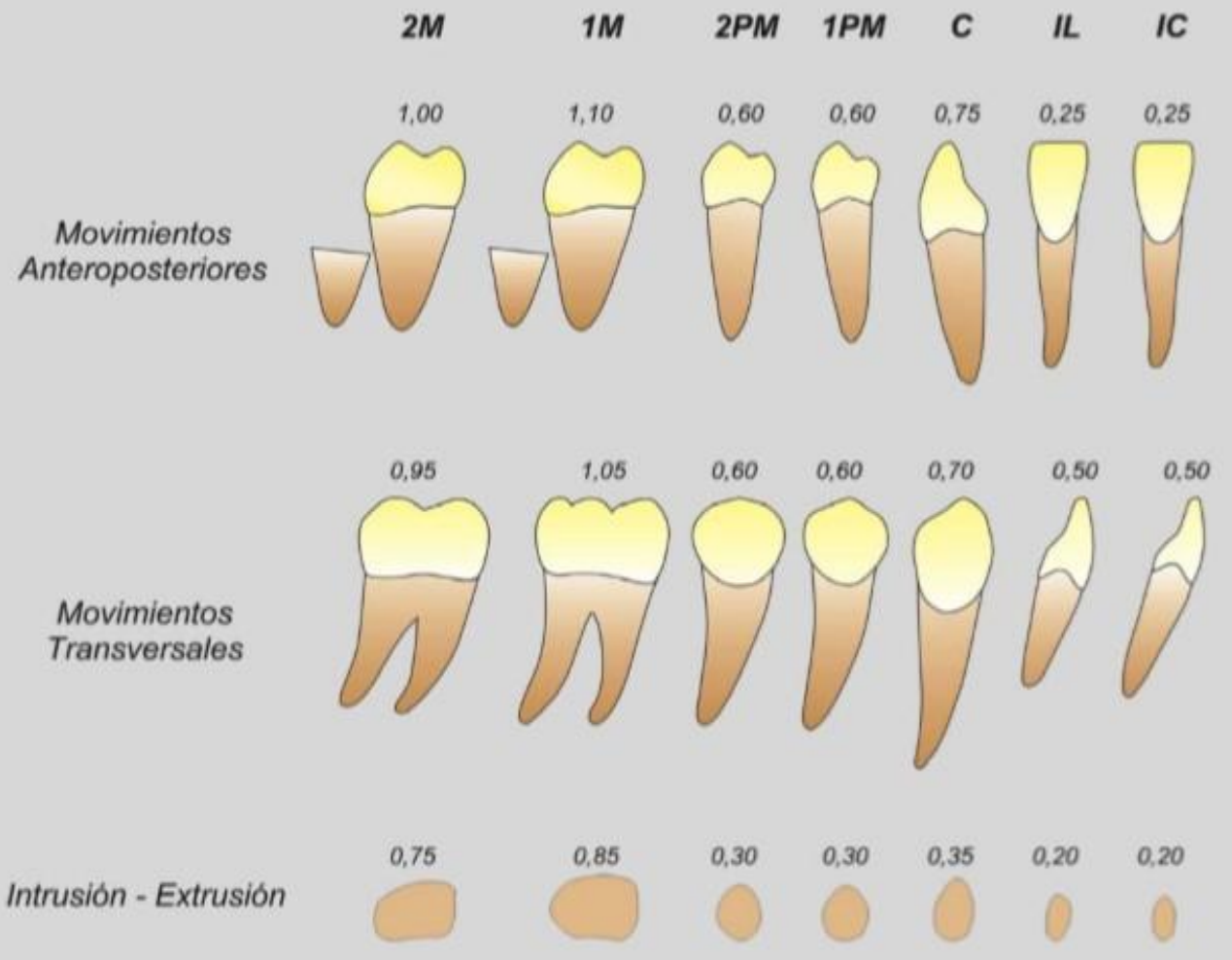

Figura 31: Superficies radiculares que se oponen al movimiento en el maxilar inferior.

DOI 10.52887/RUOO/v4n2.7 RUOO 2021 Vol 4 No1 jul-dic2021 3-38 


\section{INTRUSIÓN ANTERIOR}

Según el propio J. Gregoret, tanto la intrusión superior como inferior asisitida por anclaje esqueletal está indicada para casos donde la cantidad necesaria de movimiento exceda los límites de la mecánica tradicional. La sobremordida anterior, la mayoría de las veces, es solucionable mediante otro tipo de terapéuticas que no involucren la colocación de minitornillos (ya sea arco utilitario, curva reversa, topes anteriores, cantilever, etc). Adicionalmente existen complicaciones anatómicas para la colocación de minitornillos, sobre todo en la línea media, donde debemos considerar primero que nada el estado de la sutura intermaxilar, ya que si la misma no está consolidada llevará al fracaso del tornillo. A su vez, el frenillo vestibular puede irritarse con facilidad si se coloca cerca de éste un minitornillo. ${ }^{6}$

Los microtornillos están indicados especialmente para lograr intrusión de incisivos en pacientes adultos con un patrón braquifacial severo, planos oclusales convergentes y mordida profunda. Muchos adultos se presentan con exhibición mínima de los incisivos superiores lo cual significa que el problema de verticalidad se puede solucionar sólo con la intrusión de los incisivos inferiores, por lo que debemos estudiar muy bien cada caso en particular y tomar en cuenta todos los elementos. ${ }^{6}$

La convergencia de los planos oclusales admite alrededor de 2 a $3 \mathrm{~mm}$ de intrusión en el arco inferior. Para lograr una mayor intrusión en los incisivos, el plano oclusal inferior se debe rotar en sentido de las agujas del reloj alrededor de la corona de los primeros molares inferiores, sometiendo así a los premolares a una intrusión leve. La intrusión anterior es especialmente útil en los casos de sobremordida con sonrisa gingival y curvas de spee acentuadas

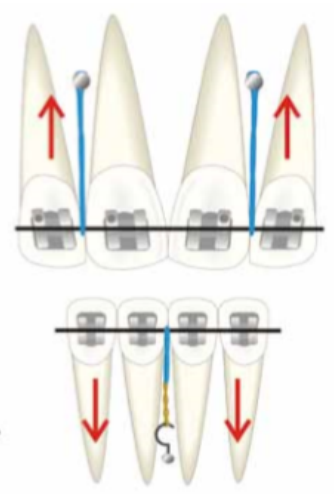

en el sector ánteroinferior por extrusión del reborde alveolar (Figura 32). ${ }^{11}$

Figura 32: Intrusión anterior.

Dicho autor deja claro que la arcada superior presenta una topografía óptima para la intrusión anterior ya que el hueso esponjoso rodea ampliamente los

DOI 10.52887/RUOO/v4n2.7 RUOO 2021 Vol 4 No1 jul-dic2021 3-38 
ápices de los incisivos, aunque en caso de que se encontrasen verticalizados, el anclaje en la tabla vestibular podría provocar inconvenientes. Diferente es la arcada inferior donde los ápices de los incisivos generalmente están en contacto con la cortical lingual y cualquier activación de intrusión deberá incorporar un movimiento de torque negativo para separarlos. ${ }^{6}$

\section{BIOMECANICA DE LA INTRUSIÓN ANTERIOR}

J. Gregoret propone al comenzar la 2da fase de tratamiento, colocar un arco $0.016 \times 0.022$ de acero el cual es suficiente para completar la maniobra de intrusión, éste arco puede ser seccionado en la zona de incisivos o continuo hasta los molares. Los minitornillos son de 5-6 mm en la arcada inferior y 6-8 en la superior, con una cabeza que permita la retención de cadenas elásticas, ligaduras conjugadas o elásticos intermaxilres. En la arcada superior, dependiendo de la separación interradicular, los tornillos se colocan entre incisivo central y lateral o entre incisivo lateral y canino. En pacientes adultos donde las suturas están consolidadas se puede ubicar un único tornillo entre los incisivos centrales, siempre y cuando lo permita el frenillo labial. En la arcada inferior la zona de preferencia es la interradicular entre incisivo lateral y canino, salvo que se cree un espacio entre las raíces de los incisivos mediante la colocación de los brackets de modo tal que separe las raíces para permitir la colocación, y luego del retiro del tornillo, reposicionar los brackets de manera correcta. ${ }^{6}$

Dicho autor plantea que la fuerza de intrusión se ejerce desde los tornillos al bracket del central o lateral o al arco, esto hace que el vector de fuerza pase por vestibular del centro de resistencia del bloque anterior lo cual genera un aumento del torque positivo y por lo tanto protrusión. En el maxilar superior la topografía de la zona anterior permite la intrusión aun generando torque positivo. Este movimiento puede ser considerado beneficioso en casos de retroinclinación, o en cambio, parásito en casos de overjet aumentado. ${ }^{6}$

En el caso que la intrusión sea realizada con arco seccional, se generarán 2 planos oclusales, uno incisivo más a gingival y otro con los caninos, premolares y molares (Figura 33 A-B). ${ }^{6}$ 


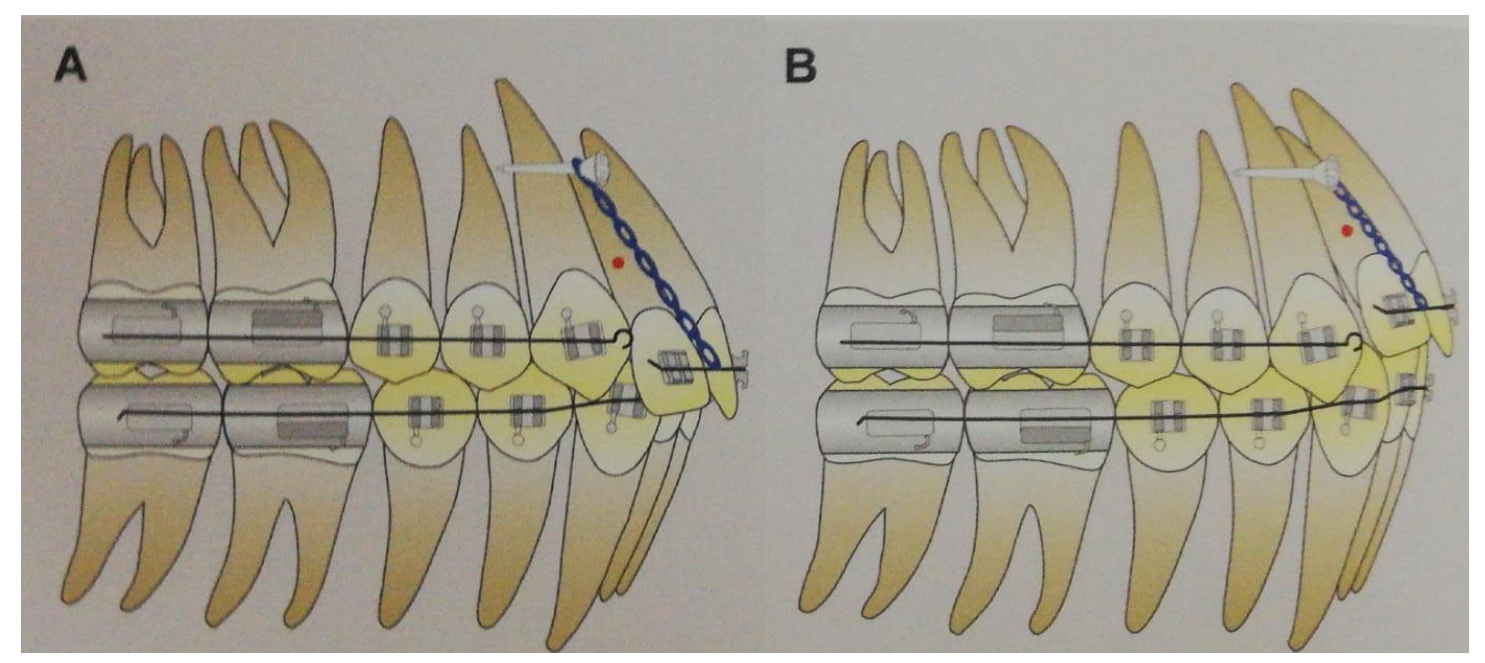

Figura 33 A-B: Intrusión del grupo incisivo superior generando escalonamiento del plano oclusal.

Una vez finalizada la intrusión deberán renivelarse los dos planos, fijando los incisivos con ligadura metálica a el/los tornillos y colocando un arco redondo de $\mathrm{NiTi}, 0.016-0.020$ dependiendo el grado de desnivel entre los planos, de molar a molar. En el caso de intrusión con arco continuo, los incisivos se intruyen al mismo tiempo que los caninos, premolares y molares evitando la aparición del plano oclusal quebrado, pero exigiendo más al anclaje, que debe resistir el movimiento de más dientes en una sola maniobra. Por lo tanto, es aconsejable cuando la magnitud de la intrusión a realizar es leve. En caso de que sea necesaria una intrusión de magnitudes importantes considero quizás más aconsejable el arco seccional anterior para evitar la necesidad de utilizar fuerzas fuertes y tener un mayor control de los movimientos. ${ }^{6}$

J. Gregoret plantea una mecánica diferente para la arcada inferior, ya que la maniobra de intrusión necesita de una activación previa de arco que genere un torque negativo para colocar los ápices radiculares dentro de la esponjosa. Esto se logra torqueando el arco negativamente o seleccionando brackets de incisivos inferiores con $-6^{\circ}$ de torque. Otra posibilidad es la colocación de un arco utilitario en el sector de incisivos torqueado negativamente, y traccionar ese sector a los minitornillos con elastómeros. ${ }^{6}$

Tanto en la intrusión superior como inferior, si durante el proceso se observa una inclinación del plano oclusal visto desde el plano frontal, se activará solamente el lado menos intruído mientras se contiene verticalmente el lado opuesto. $^{6}$

Fuerza aplicada: según el autor, las fuerzas utilizadas en el grupo incisivo superior, en el caso de arco seccionado, deben ser de un total de $180 \mathrm{~g}$, por lo tanto, si se colocan 2 minitornillos cada uno soportará unos $90 \mathrm{~g}$ de fuerza. En el grupo incisivo inferior esta fuerza debe ser menor, un total de $160 \mathrm{~g}, 80 \mathrm{~g}$ en cada tornillo. En ambos casos si se utiliza arco continuo estas fuerzas deben duplicarse. ${ }^{6}$ 


\section{INTRUSIÓN POSTERIOR}

\section{BIOMECÁNICA DE LA INTRUSIÓN POSTERIOR}

Alvarez, T. McQuattie y I. Scannone, A en la Revista Latinoamericana de Ortodoncia y Odontopediatría en el año 2010 plantean que la intrusión de piezas en el sector posterior está indicada en dos situaciones clínicas: mordidas abiertas y extrusión por falta de antagonista. Las mordidas abiertas son tratables con intrusión posterior cuando se generan en pacientes con un patrón muscular débil, el cual permite el desarrollo vertical posterior de los procesos alveolares, crecimiento que no es compensado por el desarrollo vertical de la rama mandibular, lo que origina las típicas mordidas abiertas esqueletales de los pacientes dólicofaciales. Estas extrusiones generalmente involucran en alguna medida a todas las piezas del sector posterior. La extrusión por falta de antagonista puede generarse en una o más piezas dentarias y disminuye el espacio para la rehabilitación protésica. ${ }^{12}$

Si bien la mecánica de resolución de ambas es similar, al tener orígenes o causas diferentes, la dificultad de la maniobra y el pronóstico de tratamiento son diferentes. Las mordidas abiertas involucran más que la simple extrusión dento alveolar, el cuadro se presenta con alteraciones no solo esqueletales a nivel de las bases sino también funcionales, por lo que un plan de tratamiento integral debe incluir la reeducación funcional (interposición lingual en la deglución, incorrecta fonación, disfunción respiratoria con o sin obstrucción de la vía aérea superior), y más aún sin hablamos de un biotipo con musculatura débil que aumente el riesgo de recidiva. ${ }^{12}$

En la intrusión posterior, en muchas ocasiones, puede ser muy útil contar en nuestro diagnóstico con una tomografía de la zona, sobre todo cuando en el movimiento intrusivo podemos encontrarnos en estrecha relación con otras estructuras anatómicas que debemos respetar, o al menos considerar, es el caso de las piezas posteriores del maxilar superior y su estrecha relación con el seno maxilar. Si las raíces estuvieran en contacto con la cortical, la posibilidad de intrusión quedaría limitada a 1 o $2 \mathrm{~mm}$, magnitud insuficiente en la mayoría de los casos para cerrar una mordida abierta de origen esqueletal. ${ }^{6,12}$

Otro factor a considerar es la relación de las raíces con las tablas vestibulares o palatinas, ya que piezas torqueadas negativamente o sobre-expandidas podrían demorar su movimiento intrusivo por el contacto con la cortical. Esto es importante a considerar en los molares inferiores donde la raíz vestibular se apoya en el balcón óseo perteneciente a la línea oblicua externa, requiriendo un movimiento previo de torque positivo del molar para alejarlas de este reparo anatómico. $^{6,12}$

El cambio vertical de la posición molar podría afectar la altura del hueso alveolar. De esta forma, los sacos inferiores al hueso existentes, se pueden agravar con la intrusión molar, mientras que la elevación del contorno del hueso alveolar alrededor del diente objetivo se puede nivelar mediante la 
nivelación de la corona, por lo tanto, es importante revisar el nivel del hueso alveolar antes de la intrusión. ${ }^{12}$

Para J. Gregoret es muy útil para casos de mordida abierta realizar el montaje en articulador, de esta manera, podemos simular la intrusión de las piezas posteriores mediante desgaste de las caras oclusales de cada diente en los modelos, así podremos visualizar cuáles son las piezas que participan y en qué magnitud en la manifestación del cuadro, y evaluar la cantidad de intrusión necesaria de cada pieza. ${ }^{6}$

Se utilizarán tornillos de $8 \mathrm{~mm}$ en vestibular del maxilar superior y $6 \mathrm{~mm}$ en el inferior, con una cabeza que permita la colocación de elastómeros, ligaduras conjugadas, resortes, etc. Para el rafe palatino se utilizarán tornillos más cortos, de aproximadamente $5 \mathrm{~mm}$, con una cabeza que permita colocar el elemento escogido para el caso, ya sea una ranura para una barra palatina, un botón para un elastómero, etc. En el caso de colocar tornillos interradiculares por palatino, su longitud dependerá de la cantidad de mucosa existente en la zona, para medirla se coloca un tope de goma endodóntico en una aguja carpule, se realiza contacto óseo y la distancia desde el tope hasta la punta de la aguja nos indica

el espesor de la mucosa. ${ }^{6,12}$

\section{POSICIÓN DE LOS TORNILLOS PARA LA INTRUSIÓN SUPERIOR}

En su libro "Tratamiento ortodóncico con Arco Recto", J. Gregoret plantea que las combinaciones son múltiples, para el caso de una mordida abierta, donde buscamos intruir ambas hemiarcadas, necesitaremos 2 tornillos vestibulares, uno a mesial y otro a distal del primer molar. Si únicamente traccionamos de estos tornillos, las piezas se intruirán aumentando su torque positivo, por lo tanto, se hace necesario el control del lado palatino, para ello existen 3 posibilidades, una es colocar 2 tornillos palatinos, al igual que en vestibular, uno a mesial y otro a distal del primer molar, teniendo en cuenta que no ocupen el mismo espacio interradicular que los vestibulares (Figura 34).

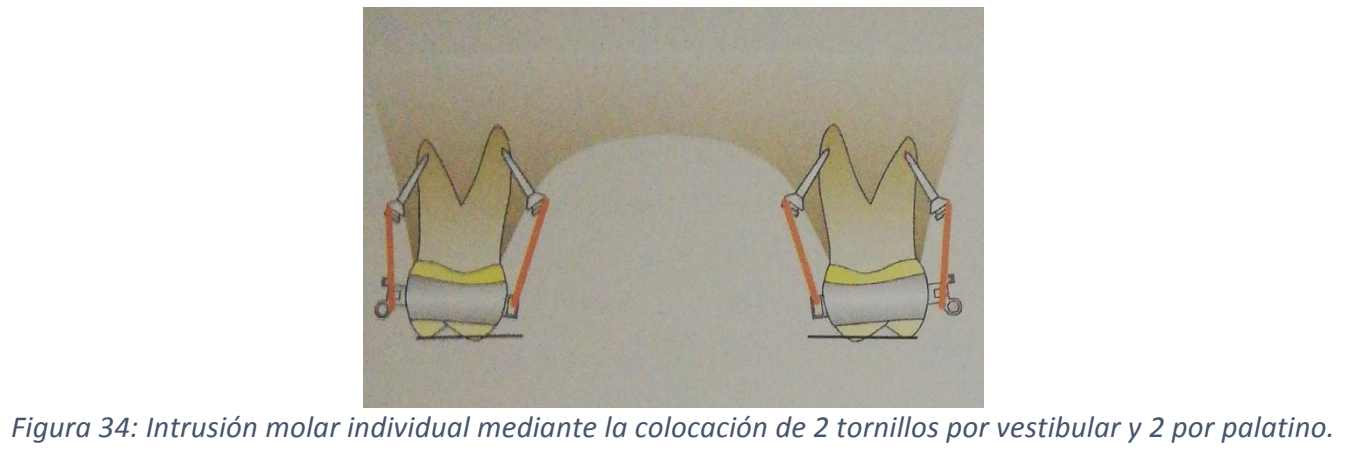

Así podremos aplicar una fuerza por palatino que se contrapone a la vestibular evitando el torque positivo. Los elementos elásticos que se utilicen para la intrusión podrán extenderse desde cada tornillo palatino a uno vestibular 
pasando por la cara oclusal de la pieza formando una $\mathrm{X}$, en algunos casos podría utilizarse un solo tornillo por vestibular y otro por palatino colocados uno a mesial y otro a distal de la pieza, uniéndolos con una cadena elástica pasando por la cara oclusal, esto podría generar algún movimiento indeseado de volcamiento de la pieza si el elemento elástico que la atraviesa no pasa por el centro de resistencia de la misma. ${ }^{6}$

Otra posibilidad es colocar un elemento elástico por vestibular y otro por palatino uniendo ambos tornillos de cada lado pasando por algún aditamento (botón, tubo, etc.) pegado en la cara correspondiente del molar (esta posibilidad también puede generar un torque indeseado si la fuerza de un lado es mayor que la del otro). ${ }^{6}$

También podemos colocar un sólo tornillo de $5 \mathrm{~mm}$ en el rafe palatino y extender desde allí el punto de aplicación de la fuerza con una barra palatina confeccionada a medida y forma del movimiento buscado (Figura 35). En los extremos de esa barra se confeccionarán loops para retener los elementos elásticos de tracción. Esta fuerza generaría un torque negativo en las piezas, para contrarrestar ese movimiento parásito colocamos tornillos por vestibular con un elemento elástico hacia el tubo de los molares. ${ }^{6}$

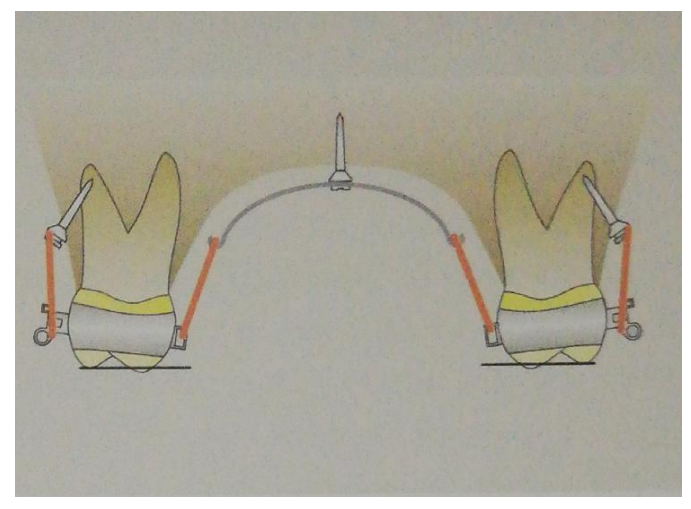

Figura 35: Intrusión de molares de ambos lados mediante la colocación de 1 tornillo en el rafe palatino y 2 vestibulares.

Otra variante sería no colocar ningún tornillo palatino y sí 2 vestibulares por mesial y distal de la pieza, y confeccionar una barra palatina tradicional que evite el movimiento de torque positivo (Figura 36$){ }^{6}$ 


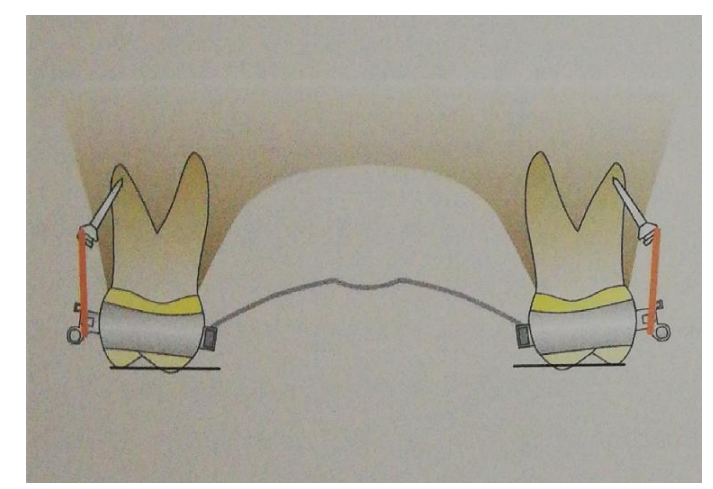

Figura 36: Intrusión de molares de ambos lados mediante ATP y 2 tornillos vestibulares.

El clínico deberá optar por una de estas posibilidades dependiendo de las características del terreno y de su propia experiencia y práctica con uno u otro sistema.

En lo personal considero importante, si el caso lo permite, dejar lo más libre posible la bóveda palatina para una mejor aceptación por parte del paciente, lo cual en muchos casos puede condicionar la colaboración del mismo en etapas futuras, evitando su cansancio con el tratamiento. Así mismo los microimplantes nos brindan una versatilidad importante en cuanto a sus posibilidades de colocación pudiendo igualar e incluso mejorar los resultados obtenidos con otras terapéuticas.

\section{POSICIÓN DE LOS TORNILLOS PARA LA INTRUSIÓN INFERIOR}

J. Gregoret dice que en la arcada inferior los tornillos se colocarán por mesial o distal de primer y segundo molar por vestibular únicamente (Figura 37). Como se mencionó anteriormente, es poco viable la colocación de tornillos en la cortical lingual por la poca estabilidad que presentan debido al poco espesor de la cortical lingual, así como también, son muy poco confortables para el paciente.

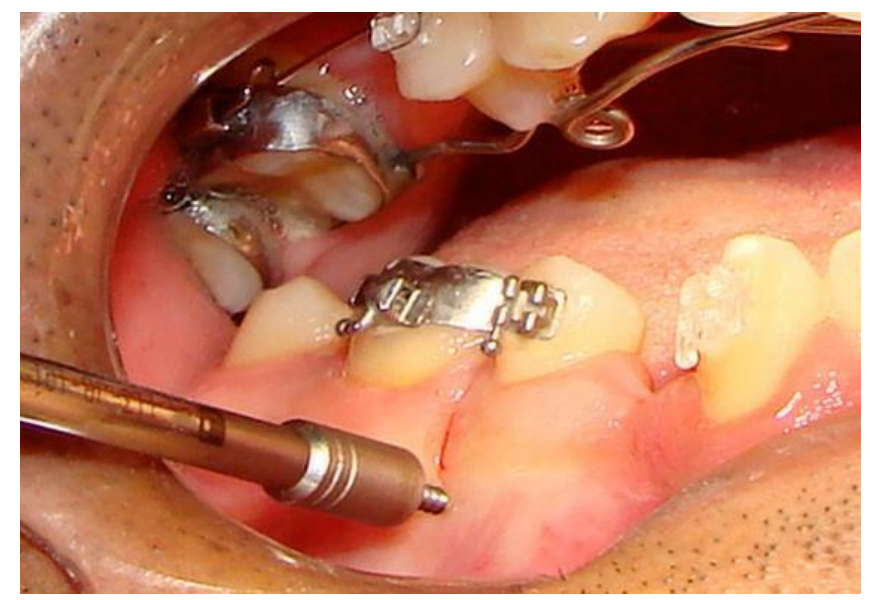

Figura 37: Colocación de microimplante para la intrusión póstero-inferior. 
Como la tracción vestibular genera torque positivo, si no se desea este movimiento se pueden torquear negativamente los arcos vestibulares rectangulares para compensar este movimiento, igualmente como se mencionó anteriormente, puede que sea necesario un movimiento de torque positivo previo a la intrusión para separar las raíces de la gruesa cortical vestibular, la cual puede limitar el movimiento o impedirlo completamente. Por ello el autor recomienda realizar una tomografía previa de la zona. ${ }^{6}$

\section{ACCIÓN, REACCIÓN Y EFECTOS PARÁSITOS}

Una vez confirmada, mediante tomografía, la presencia de hueso esponjoso hacia apical de la pieza a intruir (sobre todo en el maxilar superior por la presencia de la cortical del seno maxilar), el movimiento vertical buscado debería controlar el torque de manera de mantener las raíces dentro del hueso trabeculado. Como se mencionó, en la mayoría de los casos se hace necesaria la tracción vestibular y palatina al mismo tiempo para no generar movimientos de torque indeseados, sabiendo que el centro de resistencia de las piezas posteriores se encuentra a nivel de la furcación de las raíces. En el caso de necesitar torque positivo o negativo, para introducir las raíces en la esponjosa, la tracción se realizará únicamente desde vestibular o palatino respectivamente, o en todo caso, con mayor fuerza de un lado que del otro si se busca la intrusión con torque en un mismo momento. ${ }^{6}$

Fuerza aplicada: según el autor para intruír un único molar tanto superiores como inferiores, se necesitan $80 \mathrm{~g}$ de fuerza aproximadamente, para un premolar será de 30 a $40 \mathrm{~g}$ aproximadamente. Es decir, que si se busca la intrusión de dos molares y un premolar por hemiarcada la fuerza será cercana a los $200 \mathrm{~g} .{ }^{6}$

\section{CADENAS ELÁSTICAS VS RESORTES DE NITI}

En un estudio realizado en 2007 en la Universidad San Francisco de Quito en animales (perros), se tomaron 12 ejemplares de similares características (, edad, calidad ósea) y se los dividió en 2 grupos de 6 cada uno. Se colocaron microtornillos de titanio de 1,6 $\mathrm{mm}$ de diámetro y $6 \mathrm{~mm}$ de largo en las mismas posiciones en todos los ejemplares con el fin de intruir las piezas dentales, en el 1er grupo se realizó la intrusión con cadenas elásticas y en el 2do con resortes cerrados de $\mathrm{NiTi}$, todos con la misma fuerza $(150 \mathrm{~g}){ }^{13}$

Los resultados del estudio fueron que al cabo de 30 días se logró aproximadamente el doble de intrusión con cadenas elásticas que con resortes de NiTi (1,15 mm con cadenas elásticas y 0,63 mm con resortes). Además se observó menor daño radicular en las piezas intruidas con cadena elástica, así como también la reabsorción ósea adyacente al ápice fue mayor en las piezas intruidas con resorte. Sin embargo, estos daños no fueron de magnitudes significativas estadísticamente hablando. ${ }^{13}$

Como conclusión se puede decir que teniendo en cuenta que la cadena elástica disminuye su rango de efectividad en menor tiempo que el resorte cerrado de cromo-níquel y que éste tiene un rango de efectividad mayor en 
cuanto a la duración de la fuerza, sería lógico pensar que la reabsorción radicular se debe a una mayor duración y magnitud de la fuerza. La razón por la cual la cadena elástica obtiene mayor cantidad de intrusión que el resorte cerrado en un mismo lapso de tiempo y con una fuerza inicial de igual magnitud, sería la duración prolongada de la zona de hialinización producida por los resortes, ya que al disminuir la fuerza de la cadena elástica "rápidamente", también disminuye la zona de hialinización con lo cual se iniciaría el movimiento dental en una forma más temprana, por lo tanto, la cantidad de intrusión en un tiempo determinado es directamente proporcional a la velocidad de desaparición de la zona hialina, teniendo en cuenta que las muestras se analizaron en 30 días después de aplicada la fuerza y que una zona hialina (área necrótica) puede durar de 2 hasta 10 semanas en desaparecer. Por lo tanto, existe menor daño radicular (cemento) en la intrusión dental con cadena elástica, puesto que al disminuir su fuerza progresivamente, también disminuye el riesgo de lesión a los tejidos periodontales.

\section{¿DÓNDE ACTUAR?}

R. Nanda en su libro "Dispositivos de anclaje temporal en ortodoncia" nos dice que tanto la mordida abierta como la profunda pueden tratarse actuando tanto sobre el sector anterior como en el posterior, en la arcada superior o en la inferior, o una combinación de varias de ellas. La elección del método de tratamiento depende de las características del paciente. Dependiendo del biotipo, la extrusión molar está indicada en el braquicefálico, mientras que la intrusión incisal está indicada en el dolicocefálico y en el mesocefálico, así como también, ambos métodos pueden ser combinados. ${ }^{7}$

Otro aspecto que el autor considera importante es la rotación del plano oclusal. La extrusión de molares superiores y la intrusión de incisivos superiores provoca anterotación del plano oclusal, lo cual está indicado en casos que se presentan con una postrotación del mismo. La extrusión de molares inferiores, y la intrusión de incisivos inferiores provoca postrotación del plano oclusal, lo cual está indicado en casos que presentan anterotación del plano oclusal. ${ }^{7}$

Debemos tener en cuenta también la estética de la sonrisa, la cual depende del grado de exposición incisal y gingival. En casos de sobremordida con sonrisa gingival, la intrusión de incisivos superiores está indicada. En cambio, en casos de reducción de la exposición incisal, está indicada la intrusión de incisivos inferiores. ${ }^{7}$

\section{INTRUSIÓN POSTERIOR EN MORDIDA ABIERTA}

Según P. Echarri y col, en la Revista oficial de la Sociedad Española de Ortodoncia del año 2008, los pacientes con mordida abierta anterior causada 
por exceso de segmentos posteriores dentoalveolares, han sido tratados exitosamente con microimplantes. La mordida abierta anterior frecuentemente presenta planos oclusales que divergen anteriormente desde los primeros premolares. La intrusión de los segmentos posteriores no sólo corrige el problema oclusal, sino que también reduce la altura facial ántero inferior y la convexidad facial, debido a que la mandíbula rota sobre sí misma de manera anterior y superior en dirección contraria al movimiento de las agujas del reloj. ${ }^{14}$

Esta intrusión puede ser nivelada o inclinada. Si anteriormente los planos oclusales divergen a partir del molar se indica una intrusión inclinada la cual se logra sometiendo a una intrusión posterior mayor, de manera diferenciada. Por otra parte, si los planos oclusales divergen en el lado anterior a partir del canino, podría indicarse una intrusión nivelada. ${ }^{14}$

Los sistemas de fuerza necesarios para lograr intrusiones niveladas o inclinadas son diferentes. En la intrusión nivelada, se necesita una fuerza que pase a través del centro de resistencia (Cres) del segmento posterior para producir translación. En la intrusión inclinada, se necesita más bien una fuera que pase distalmente al centro de resistencia para lograr intrusión diferenciada, más sobre el molar que sobre el premolar. En general, el centro de resistencia de este sector comprendido entre 1er molar y 1er premolar se encuentra entre el 1 er molar y el 2 do premolar. $^{14}$

La intrusión de este segmento es más fácil de lograr con un sistema de placas que con minitornillos, especialmente si se desea la intrusión inclinada del segmento. Un minitornillo podría interferir con el movimiento de los dientes, sin embargo, el sistema de placas proporciona al clínico más versatilidad ya que no existe la preocupación del daño radicular. ${ }^{14}$

Los minitornillos constituyen una opción viable si lo que se va a corregir es una intrusión nivelada del plano oclusal. Debido a que el espacio interradicular es limitado, cualquier fuerza que no pase por el Cres del diente causará un movimiento que podría inclinar las raíces hacia el minitornillo. Para prevenir esto, el minitornillo deberá ser utilizado inicialmente para someter al molar a intrusión separadamente. Luego, los premolares podrán ser sometidos a intrusión directa o indirectamente después de conectar, de forma rígida, el molar al tornillo. Otra alternativa es agregar otro minitornillo entre las raíces de los premolares. Esto permitiría controlar la inclinación del segmento posterior en la medida que sean aplicadas las fuerzas de intrusión a partir de los dos tornillos adyacentes. ${ }^{14}$

Desde el punto de vista sagital, mientras se ejerza fuerza sobre el segmento posterior en forma distal a su centro de resistencia, se observará una rotación en sentido de las agujas del reloj. Para controlar esta rotación algunos han propuesto añadir un minitornillo más anteriormente. Una alternativa es aplicar la línea de acción más cerca del Cres del segmento. Otra opción es unir uno de los extremos del molar, fijando la distancia vertical al minitornillo y aplicando una fuerza al otro extremo del segmento luego de extender un brazo desde el minitornillo. ${ }^{14}$ 


\section{ASPECTOS TÉCNICOS}

El mismo autor señala que para la corrección de una mordida abierta mediante intrusión de los sectores posteriores se configurará el arco superior colocando 2 arcos seccionales de acero $0.017 \times 0.025$ en ambos lados desde el 2 do molar hasta el 1er premolar. El segmento anterior incluye a los incisivos superiores con un alambre de iguales dimensiones. El canino se incluye bien sea en el segmento anterior o en el posterior, dependiendo de la relación vertical con respecto a los dientes adyacentes y su posición vertical estimada. En muchos casos, el canino no deberá ser inicialmente conectado a ningún segmento, sino más bien al arco ortodóntico después de que el sector posterior ha sido intruído. Conectar el canino inicialmente al segmento posterior podría causar su extrusión si la fuerza de intrusión se aplica al 1er o al 2do molar. ${ }^{14}$

Se aplica la misma mecánica al arco inferior si el plano oclusal diverge anteriormente de manera significativa desde el 1er premolar, sin embargo, la divergencia severa en el arco inferior es poco común, de manera que podemos colocar un arco ortodóntico contínuo antes de colocar la fuerza de intrusión. En el caso de que busquemos la intrusión en una sola arcada, debemos controlar la arcada antagonista con algún dispositivo de anclaje para evitar la sobreerupción del sector. ${ }^{14}$

\section{INTRUSIÓN MOLAR EN FORMA INDIVIDUAL}

Segùn R. Nanda un molar extruido requiere una intrusión pura a lo largo del eje longitudinal del diente, sin extrusión de los dientes adyacentes. Es fundamental proporcionar una línea de fuerza que pase a través del centro de resistencia (Cres) tanto en el plano sagital como transversal, para prevenir una posible inclinación buco-lingual o mesio-distal durante la intrusión. Se estima que el Cres del primer molar superior esté en el centro de la tabla oclusal, cerca de la raíz palatina. La línea de fuerza debería pasar a través del Cres aproximado del molar, a lo largo del eje central, en el plano oclusal. Los puntos de inserción recomendados para los minitornillos son, por lo tanto, el área interdentaria mesial sobre la superficie vestibular y el área interdentaria distal sobre el lado

palatino, o vice

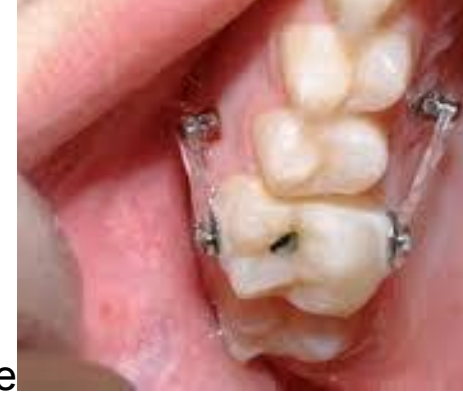

fuerza bilateral combinada de los lados vestibular y palatino, producirá una línea de fuerza que pasa a través del Cres del molar, induciendo una intrusión pura sin inclinación. ${ }^{7}$ 
La aplicación de esta fuerza se puede realizar colocando un aditamento (botón) en cada cara libre dentaria, idealmente deberán colocarse sobre la línea recta imaginaria que une ambos tornillos para, de esta forma, evitar la rotación de la pieza al momento de colocar el elemento elástico que una estos aditamentos a los respectivos microimplantes (Figura 38 a y b). ${ }^{7}$

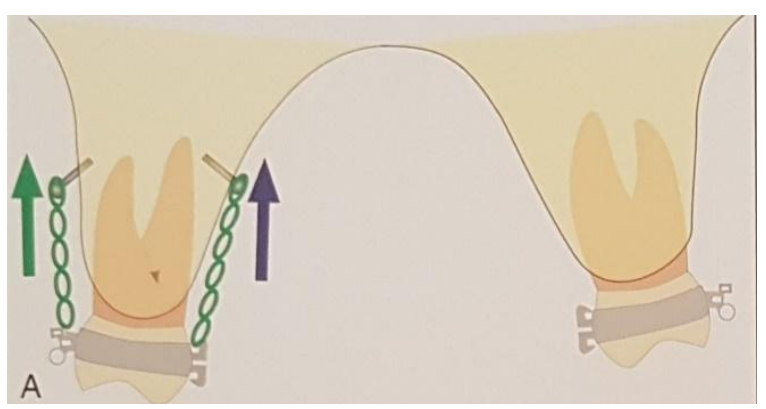

Figura 38 a y b: Intrusión molar individual con un tornillo por vestibular y otro por palatino conectados a botones de las caras libres mediante cadenas elásticas.

Una segunda opción sería no colocar aditamentos y colocar una cadena elástica de un tornillo hacia el otro, pasándola por encima de la cara oclusal. Ésta última opción, si bien es más simple, implica que el elemento elástico (cadena) estaría sometido a las fuerzas de la oclusión lo cual nos genera dos posibles inconvenientes como lo son la molestia por parte del paciente debido a la interferencia oclusal y la posibilidad de rotura de la cadena elástica y la consiguiente recidiva del movimiento logrado. Así mismo es una técnica que no proporciona un control eficaz de los diferentes movimientos, pudiendo generarse movimientos parásitos (Figura 39 a, b y c). ${ }^{7}$
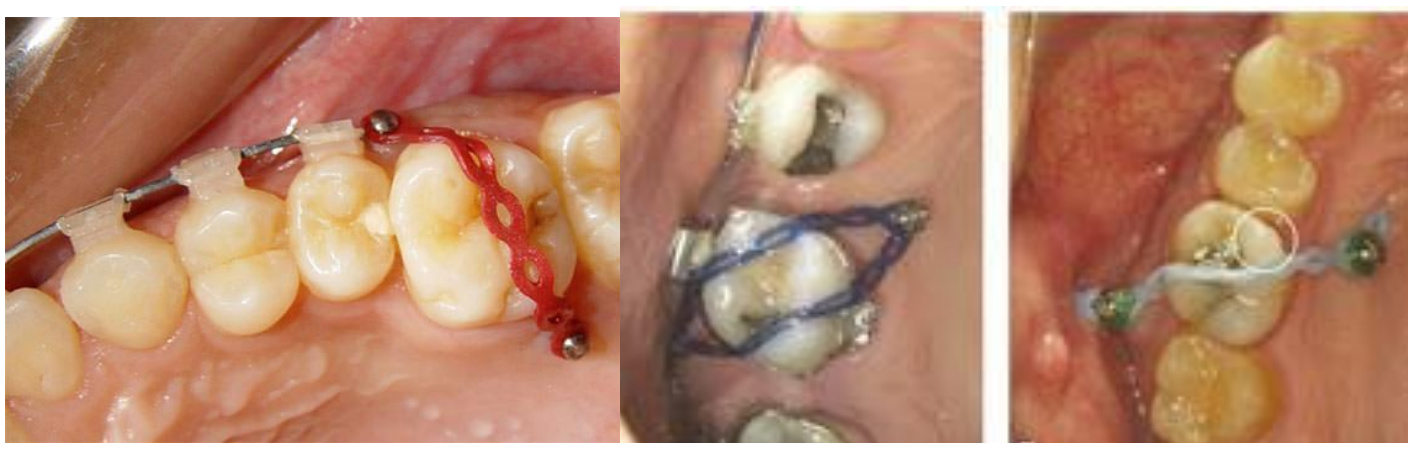

Figura $39 a$, b y c: Intrusión molar individual mediante la colocación de 1 tornillo vestibular y otro palatino unidos mediante una cadena elástica que pasa sobre la cara oclusal.

Otra posibilidad que nos brinda el autor es colocar 2 microimplantes por vestibular, uno a mesial y otro a distal de la pieza y 1 por palatino más alejado de la zona interradicular pero siguiendo el eje vertical de la pieza para evitar su volcamiento mesial o distal. De ésta manera se coloca un elemento elástico uniendo ambos tornillos vestibulares pasando por encima del aditamento vestibular de la pieza, del lado palatino se aplica la fuerza desde el tornillo hacia el aditamento colocado en el centro de la cara palatina (siempre siguiendo el eje vertical de la pieza). Ésta técnica nos brinda un mayor control tanto del torque como de la rotación (Figura 40). ${ }^{7}$ 


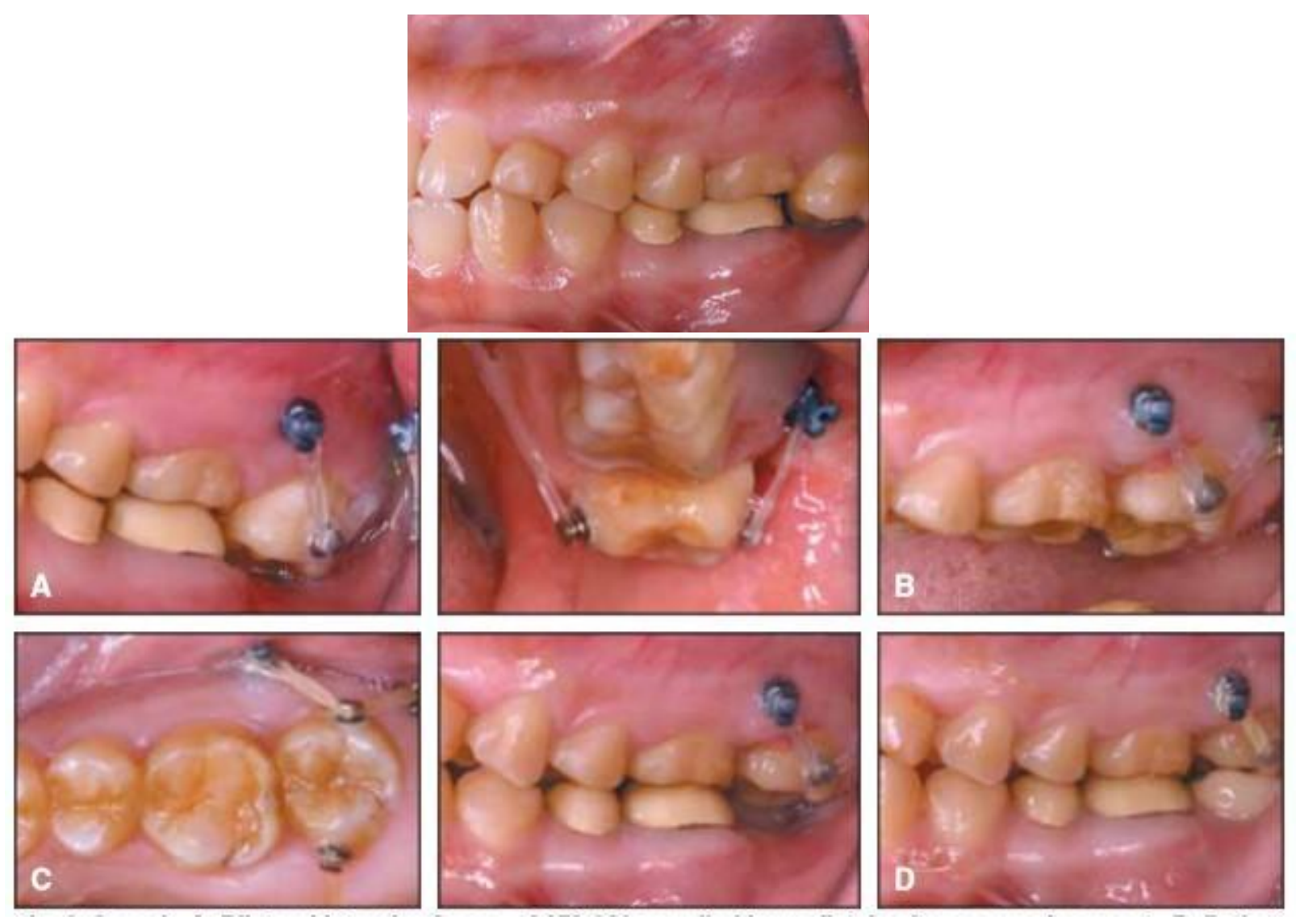

Figura 40: Pasos para la intrusión molar mediante la colocación de 2 tornillos vestibulares y uno palatino.

Como ya se mencionó, los dispositivos pasivos o activos se pueden utilizar para controlar el momento de la fuerza de intrusión. El dispositivo pasivo recomendado es el ATP, sin embargo, el momento de la fuerza de intrusión podría ser difícil de contrarrestar a pesar de la rigidez del ATP. Por ello, podría ser mejor colocar un arco ortodóntico más pesado, como puede ser el expansor palatino Hyrax. Este expansor también puede controlar de manera activa los efectos colaterales de la inclinación vestibular si se coloca con el tornillo abierto. Sin embargo, cualquiera de estos dos elementos auxiliares de anclaje cruzado nos imposibilita el movimiento de intrusión puro unilateral sin consecuencias para el molar de la hemiarcada opuesta. En estos casos de intrusión unilateral, cuando contamos con un único minitornillo por vestibular del molar a intruír, para disminuir el efecto parásito de volcamiento palatino en el molar contralateral y de volcamiento vestibular del propio molar, se deberá pre-torquear el ATP dándole un componente de torque positivo al molar opuesto y por el contrario, de torque negativo al molar a intruir (Figura 41 a y b). ${ }^{7}$ 


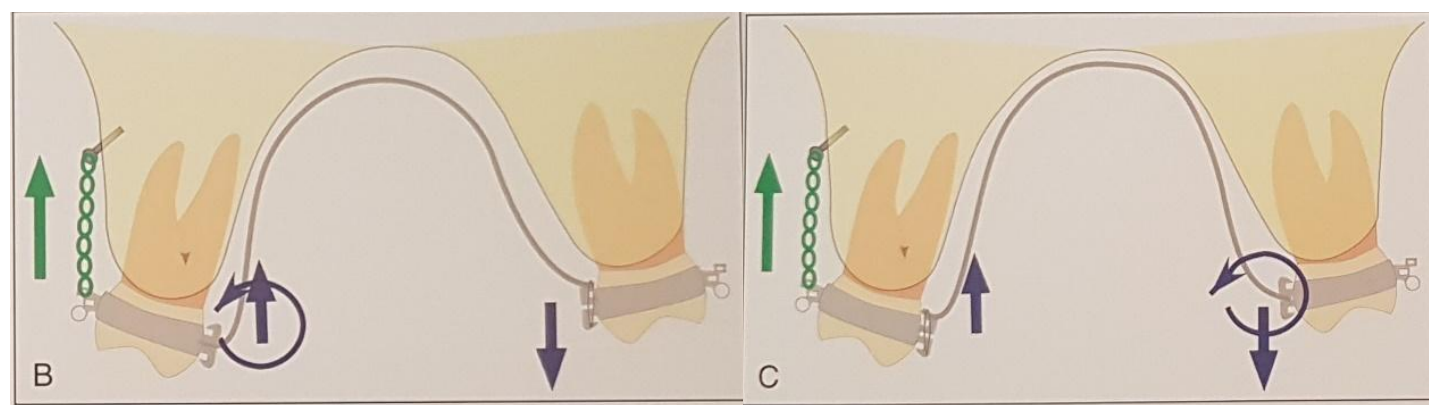

Figura 41 a y b: Debemos pre-torquear el ATP para evitar movimientos parásitos.

Otra posibilidad para alcanzar la intrusión molar desde un lugar distante, usando un sistema de fuerzas de anclaje directo, involucra la colocación de un único minitornillo en el paladar. En este caso el movimiento de intrusión no será paralelo al eje dentario porque el vector de la fuerza no pasa por el Cres. Para mejorar esto se fabrica un elemento colado que oficie de brazo de extensión desde el tornillo, pasando cerca de la mucosa palatina y finalizando a gingival de la corona del molar en cuestión. De esta forma se logra un vector de fuerza más vertical, con un menor volcamiento dentario hacia palatino (Figura 42). ${ }^{7}$

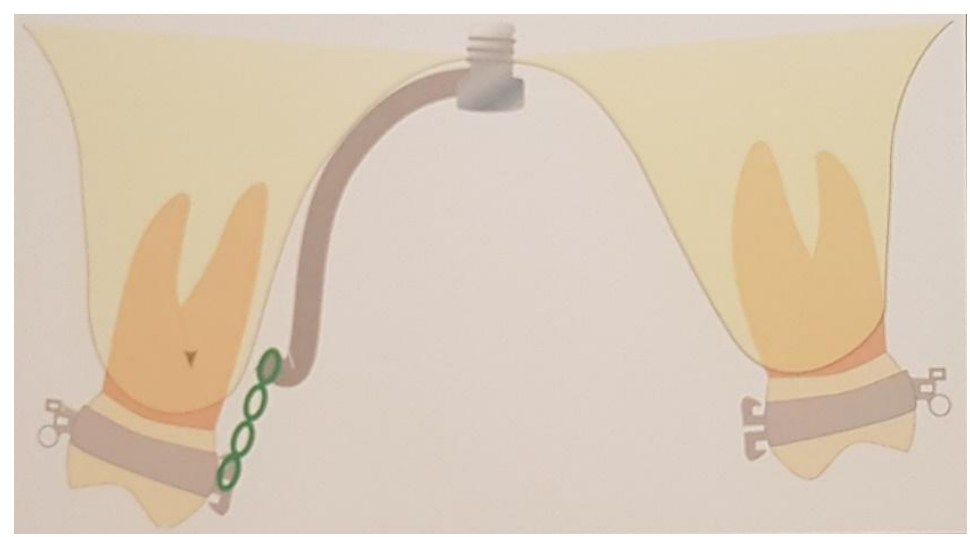

Figura 42: Intrusión mediante microimplante colocado en el rafe medio y brazo colado.

Otra opción es la colocación de un minitornillo por vestibular en el área de bifurcación, si bien técnicamente es posible, el clínico deberá considerar la magnitud de la intrusión molar requerida. Una intrusión extensa probablemente ocasione la colocación elevada del minitornillo en el vestíbulo, lo cual usualmente da como resultado, la irritación del tejido blando. ${ }^{7}$

Si queremos intruir dos molares adyacentes de similares superficies radiculares podemos lograrlo de manera eficiente con dos minitornillos insertados en las áreas interproximales vestibular y palatina. Se espera que el centro de resistencia esté localizado por debajo del contacto proximal. Dos minitornillos colocados en el área interdental proximal producen una línea de fuerza cercana al centro de resistencia, conduciendo a una intrusión por segmentos sin tornillos adicionales. ${ }^{7}$ 


\section{MANEJO VERTICAL DE UNA ARCADA COMPLETA}

Por último, vamos a nombrar una serie de posibilidades de corrección de ciertas disgnacias manejando una arcada como una única unidad.

Podemos encontrarnos con planos oclusales canteados, o sea, aquellos que vistos en el plano frontal presentan un lado más elevado que el opuesto, esto lo podemos ver fácilmente en una fotografía de frente del paciente, trazando el plano oclusal y comparándolo con la línea bipupilar. Si queremos realizar un estudio pormenorizado de ese plano y las posibles asimetrías asociadas podemos realizar el cefalograma frontal del Dr. Ricketts. Este tipo de planos por lo general puede encontrarse asociado a otras maloclusiones, pero aquí sólo nos enfocaremos en las posibilidades de corrección del mismo. Un elemento importante a tener en cuenta es el estudio del tercio facial inferior, ya que en éste tipo de terapéuticas podremos modificarlo. ${ }^{7}$

Hay múltiples posibilidades de colocación de minitornillos con distintos aditamentos y en variadas posiciones, pero aquí vamos a referirnos únicamente al objetivo que queremos lograr. Si queremos aumentar el tercio inferior podemos fijar la hemiarcada superior que se encuentra más alejada de la línea bipupilar con microimplantes, así como también la hemiarcada inferior opuesta (la más cercana a la línea bipupilar). Dicha fijación se puede realizar simplemente con alambre desde los microimplantes hacia el arco. Luego que tenemos ambas hemiarcadas fijas podemos utilizar gomas intermaxilares para mover las hemiarcadas antagonistas y nivelar el plano aumentando el tercio inferior. Si queremos disminuir o mantener ese tercio inferior debemos intruir las hemiarcadas primero antes de fijarlas.

Dependiendo las características del caso clínico y los objetivos que se persigan, podremos realizar una intrusión de mayor o menor magnitud e incluso realizar nuestra intrusión o fijación en una sola hemiarcada (un solo cuadrante). El especialista debe conocer todas las posibilidades para luego inclinarse por la que considere será la más beneficiosa para el paciente.

Existen otros casos en los que los objetivos finales del tratamiento nos demandan la intrusión de toda una arcada, en este caso nombraremos posibilidades de intrusión completa superior. Este tipo de intrusión es una maniobra que está siendo puesta en práctica con éxitos dispares en el objetivo de evitar someter al paciente a una cirugía por Le Fort 1 de impactación.

En los casos que se podría indicar la intrusión completa superior es cuando el paciente presenta una mordida profunda anterior y extrusión póstero superior por falta de antagonistas inferiores, cuando no queremos aumentar el tercio inferior. Otro ejemplo, es si el paciente presenta una mordida abierta anterior y sonrisa gingival. Las magnitudes de la intrusión en cada sector de la arcada variarán con el caso clínico y necesidad de tratamiento. Si bien los éxitos han sido dispares, no deja de ser otra herramienta que debemos conocer y tener "bajo la manga". 


\section{CASOS CLÍNICOS}

A continuación detallaremos 3 casos clínicos que ejemplifican algunas de las situaciones más comunes a las cuales nos enfrentamos en la práctica diaria en lo que se refiere a problemas verticales.

\section{CASO 1: TRATAMIENTO DE LA MORDIDA PROFUNDA ANTERIOR CON EXTRACCIONES. ${ }^{15}$}

La paciente presentaba una maloclusión de clase II, 2 (Figuras del 43 al 46). El tratamiento se realizó con extracción de los primeros premolares superiores izquierdo y derecho.

En las fotos iniciales intrabucales (Figuras 43 y 44 ) observamos la magnitud de la mordida profunda. Se puede observar la reciente extracción de la pieza 24.
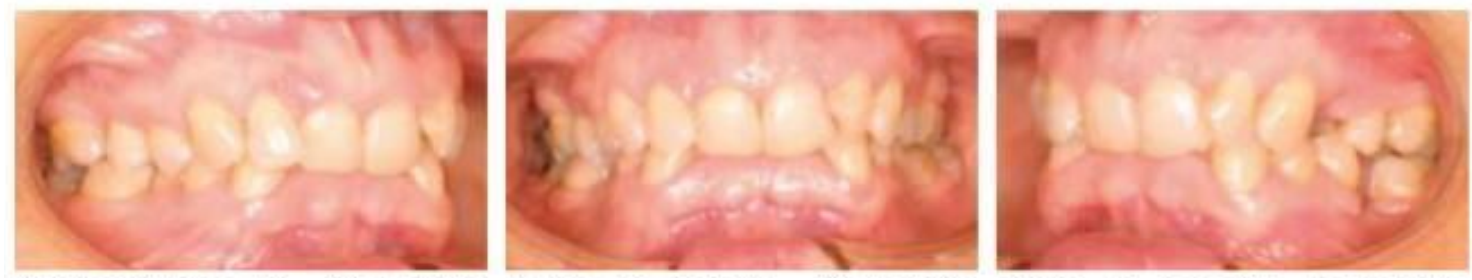

Figura 43: Fotos intrabucales iniciales de frente y perfil.
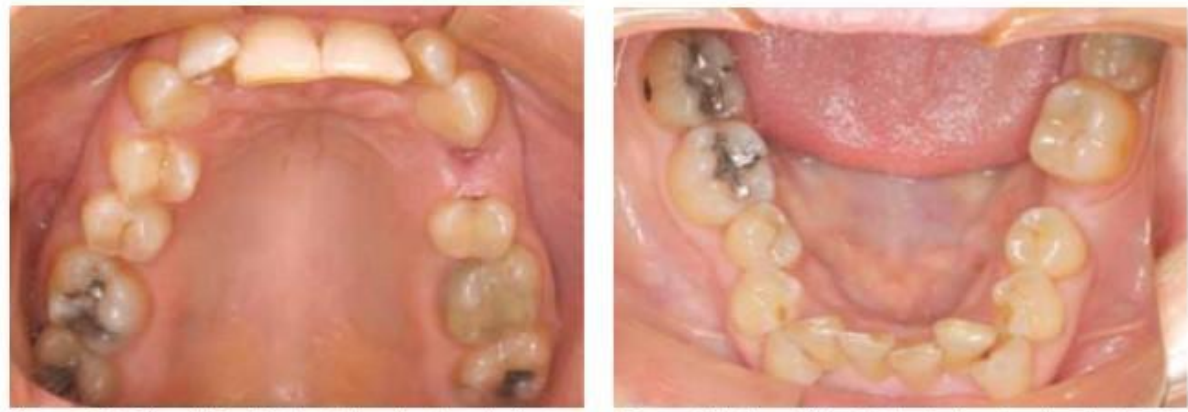

Figura 44: Fotos intrabucales iniciales superior e inferior.

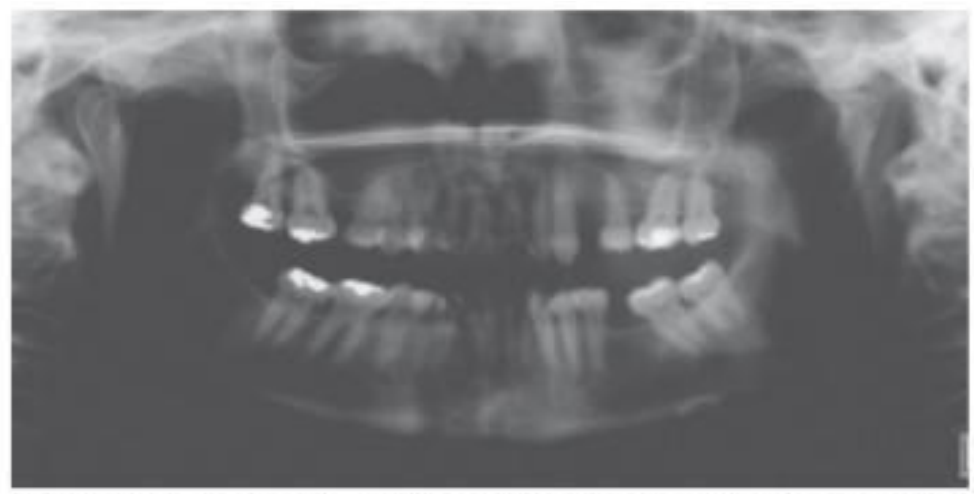

Figura 45: OPT Inicial 

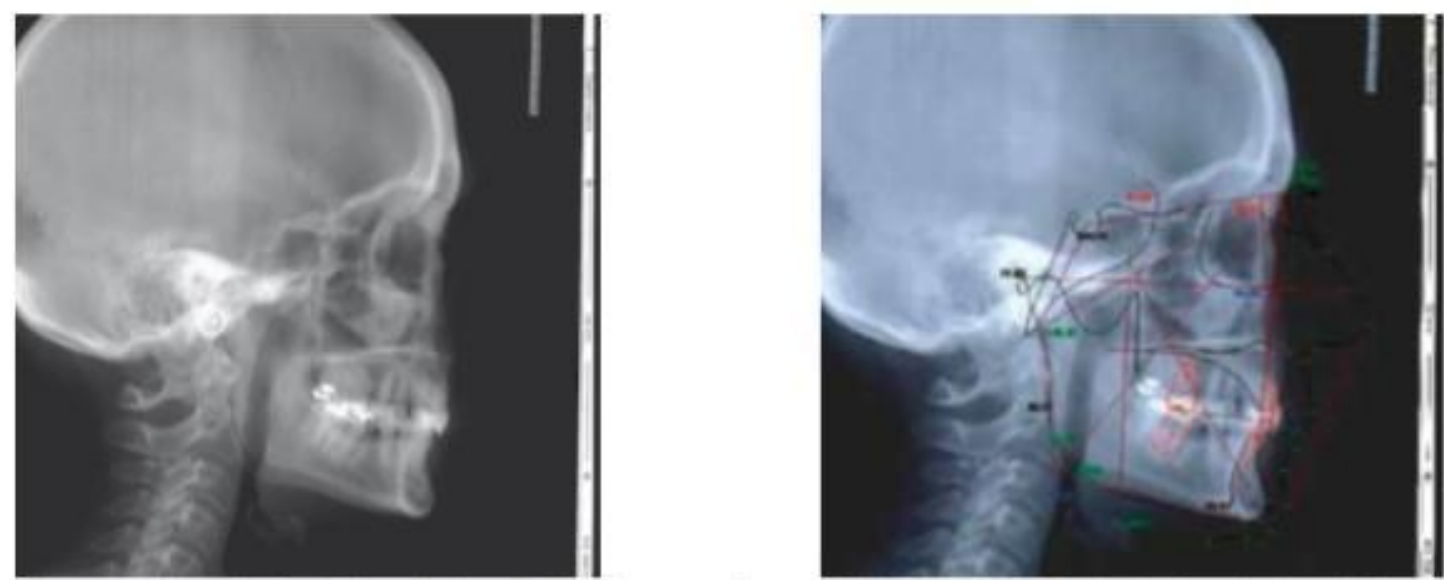

Figuras 46 a y b: Telerradiografía de perfil y trazados iniciales.

La alineación se realizó con un arco $0.016 \mathrm{NiTi}$. A continuación, se estableció el torque con un arco $0.016 \times 0.022 \mathrm{NiTi}$. Para el cierre de espacios se utilizó un arco de $0.016 \times 0.022$ de acero. Se insertaron microimplantes Ancor Pro de 8 $\mathrm{mm}$ de longitud y $1,6 \mathrm{~mm}$ de diámetro entre caninos y 2 dos premolares en ambos lados de la arcada superior (Figuras 47 y 48 ).
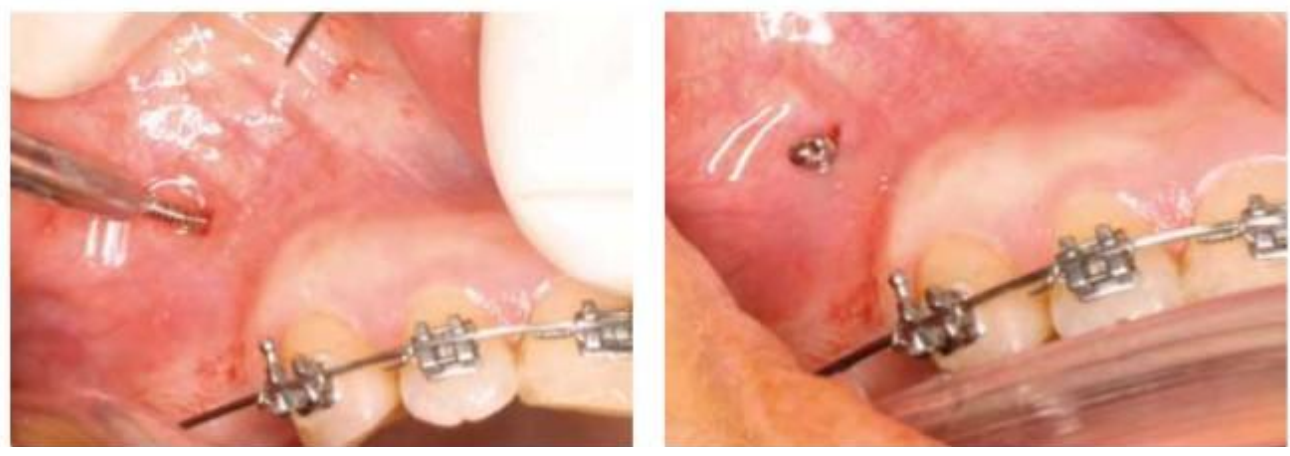

Figura 47: Inserción del microimplante derecho.
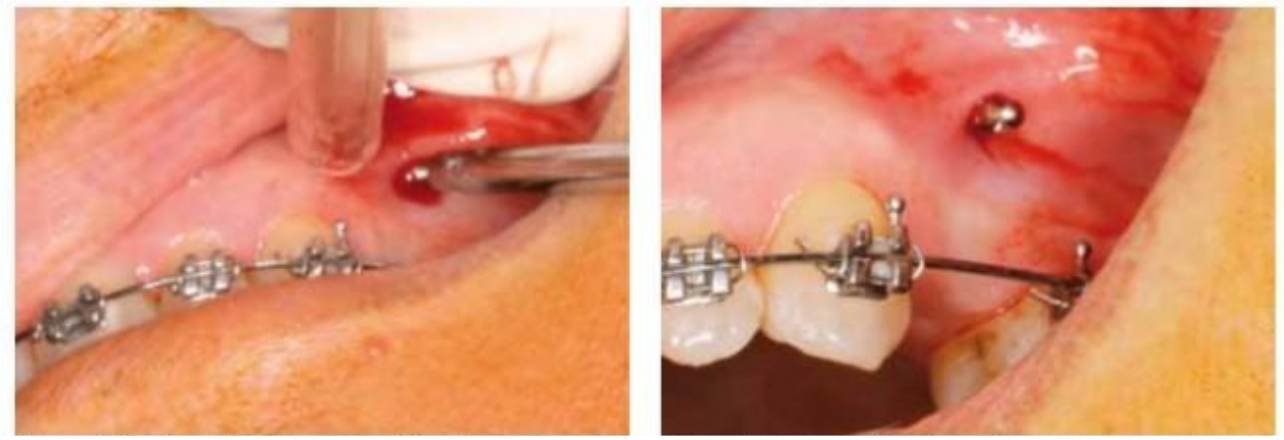

Figura 48: inserción del microimplante izquierdo.

Como el microimplante derecho tenía una posición más alta que el izquierdo, se utilizó un "hook" en el lado derecho más largo que el "hook" en el lado izquierdo. De esta forma se consiguió realizar fuerzas simétricas y evitar la inclinación del plano incisal. Los microimplantes se colocaron en una posición 
más alta que los "hooks" para producir retrusión e intrusión simultáneamente al aplicar fuerzas con una dirección divergente al arco (Figuras: 50 y 51). En la mandíbula se usó una mecánica convencional con la colocación de un mantenedor de espacio. La evolución del caso y los resultados finales pueden observarse en las figuras 52 a 54.
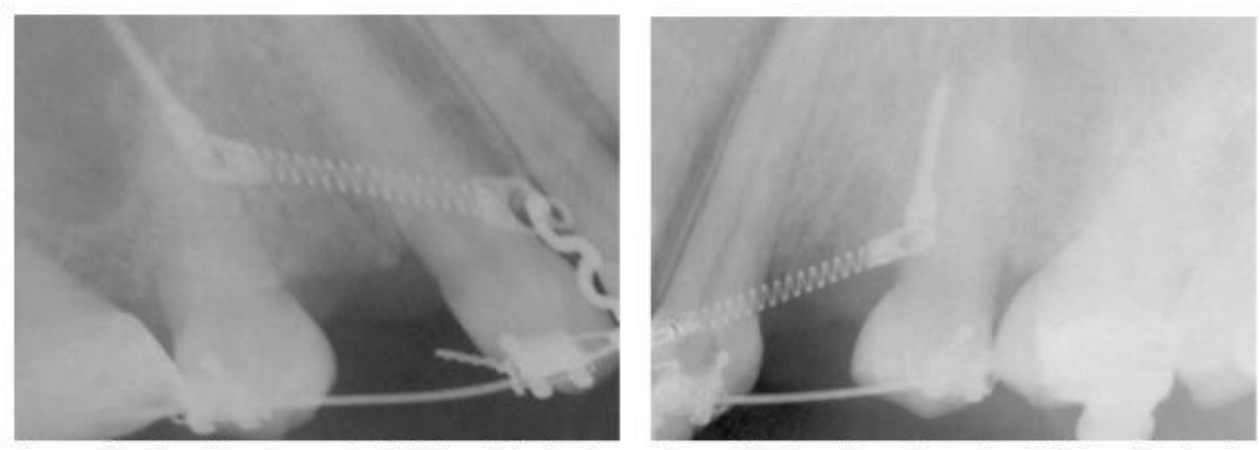

Figura 49: Control radiográfico de ambos microimplantes.
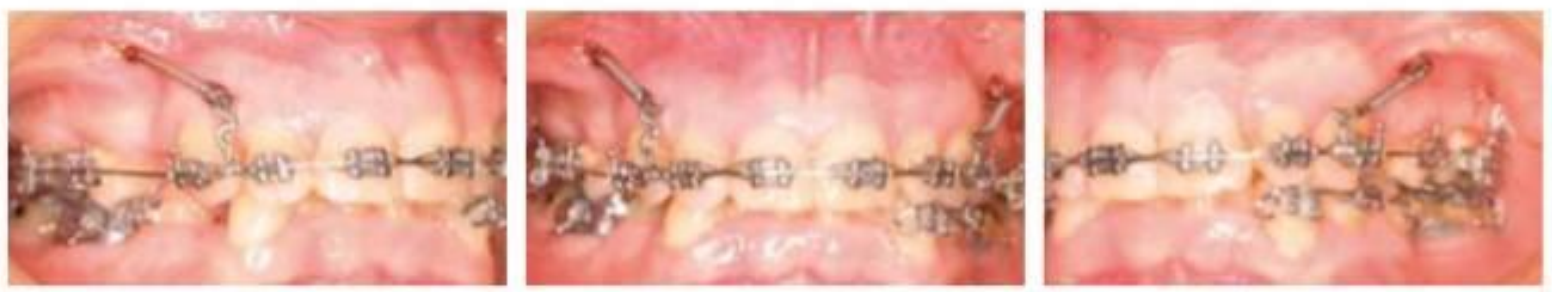

Figura 50: Tracción desde los microimplantes con resortes de espiras cerradas a postes crimpables instalados entre lateral y canino. Como el microimplante derecho está más alto que el izquierdo se utilizó un poste más largo de ese lado para evitar la rotación del plano oclusal. Vista izquierda, frontal y derecha.

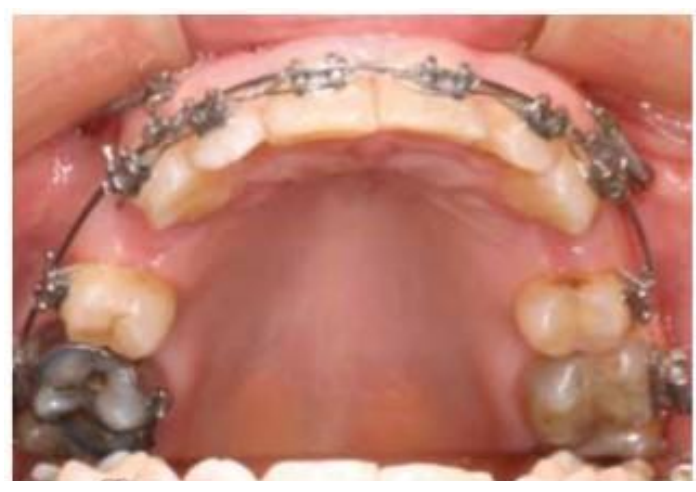

Figura 51: Vista superior. 

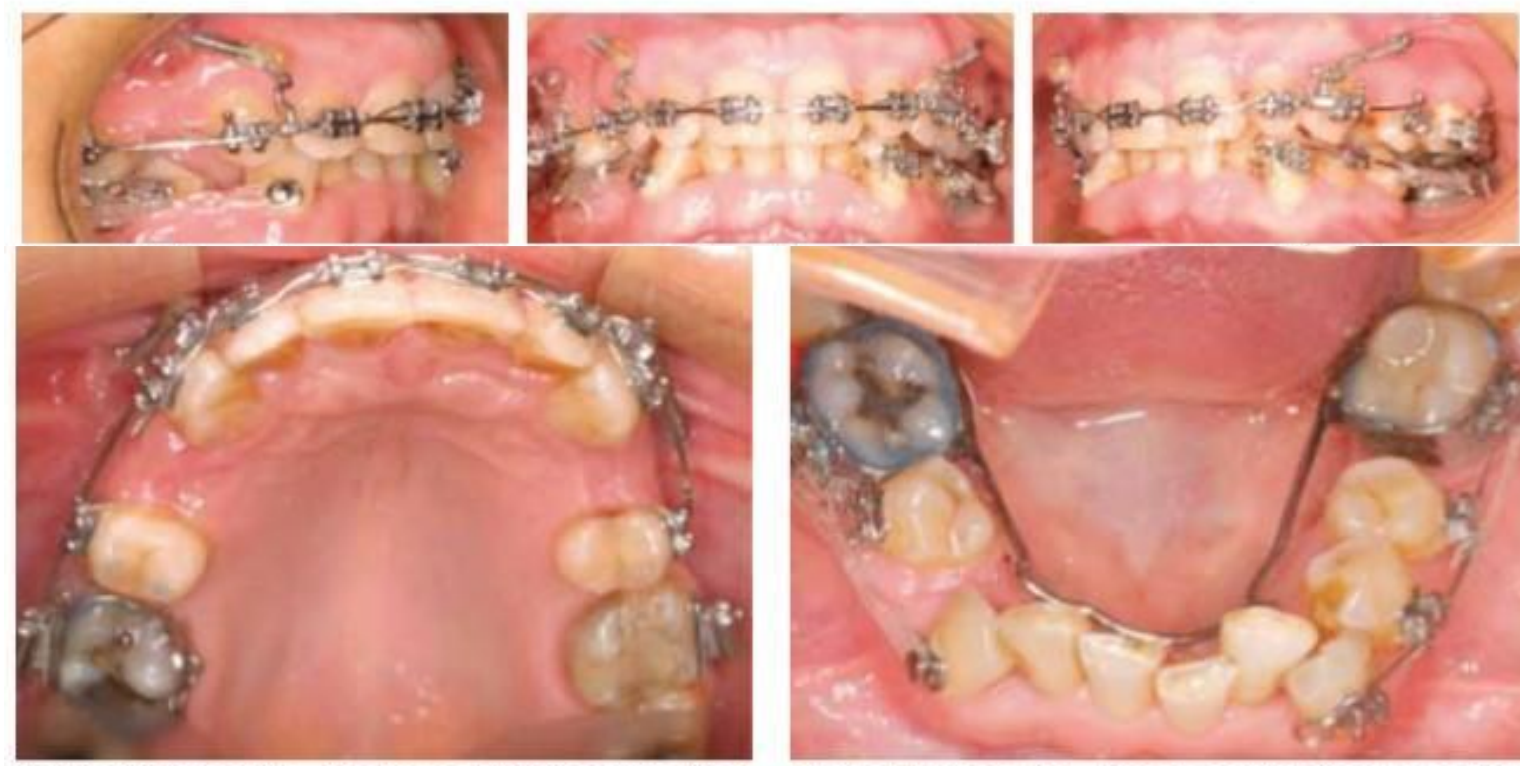

Figura 52: Progreso del tratamiento.
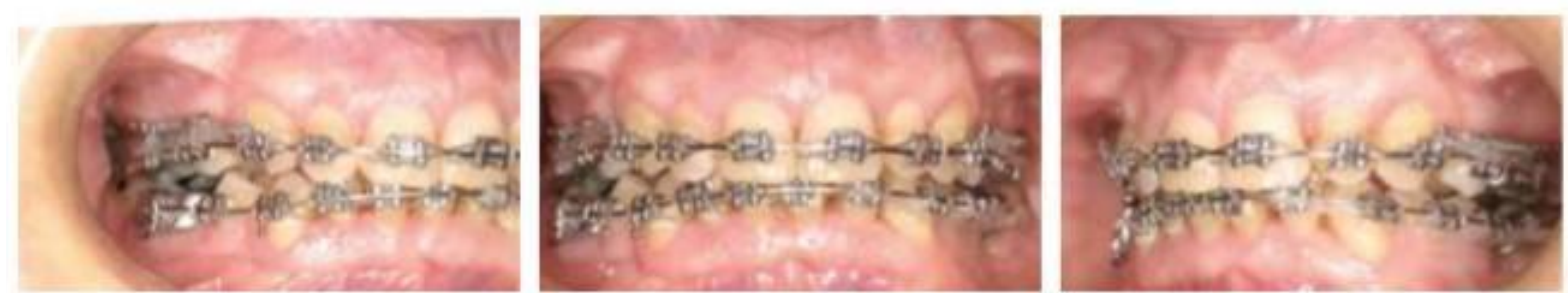

Figura 53: Progreso del tratamiento ya con aparatología inferior instalada completamente.
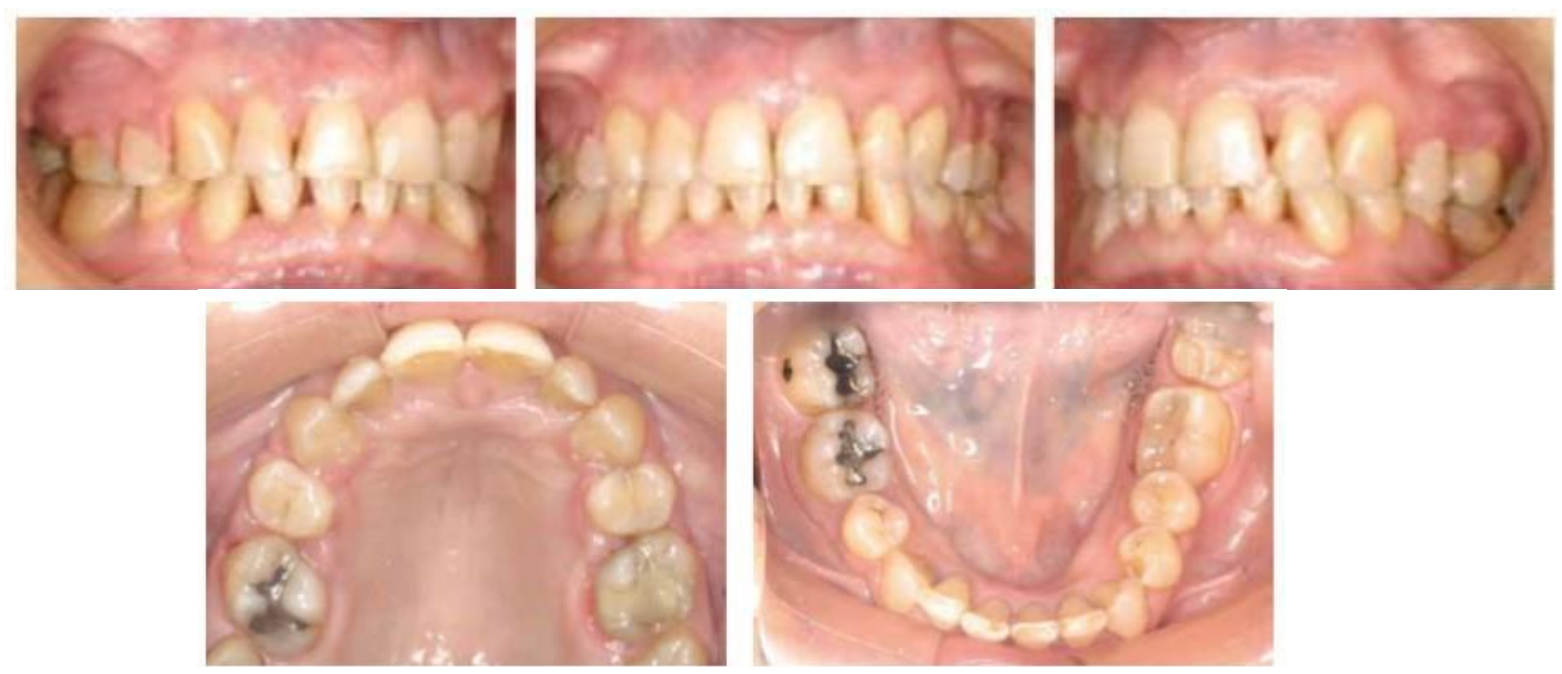

Figura 54: Finalización del caso. 
Podemos establecer un protocolo del tratamiento de la mordida profunda anterior con extracciones con retrusión e intrusión de incisivos utilizando microimplantes en base a este caso clínico:

- Alineación y nivelación con arco $.016 \mathrm{NiTi}$.

- Establecimiento de torque con arco $.016 "$ x .022 NiTi.

- Intrusión con arco .016 x .022 de acero, postes crimpables, microimplantes y cadena elástica o resorte de espiras cerradas.

- Terminación con arco .017 x .025 de acero.

\section{CASO 2: INTRUSION POSTERIOR. ${ }^{16}$}

Paciente de 18 años de edad, sexo masculino, sistémica y periodontalmente sano. Desde el punto de vista esquelético presenta una relación sagital intermaxilar de clase I, prognatismo maxilo-mandibular moderado a causa de macrognatismo superior e inferior moderado, biotipo dolicofacial, patrón de crecimiento vertical moderado. Proinclinación y protrusión moderada de incisivos superiores (Figuras 56 y 57). Desde el punto de vista dental presenta una dentición permanente adulta, clasificación Angle clase I Molar y clase canina no aplica, línea media superior desviada $1 \mathrm{~mm}$ a la derecha, mordida abierta anterior desde caninos (Figuras 55 y 58). En los tejidos blandos observamos un ángulo naso labial agudo y biproquelia (Figuras 55 y 57). El diagnóstico funcional es la interposición lingual. El tratamiento planteado es alinear y nivelar sin exodoncias ni manejo quirúrgico, cerrar mordida a expensas de intrusión controlada del sector posterior por medio de microimplantes. 

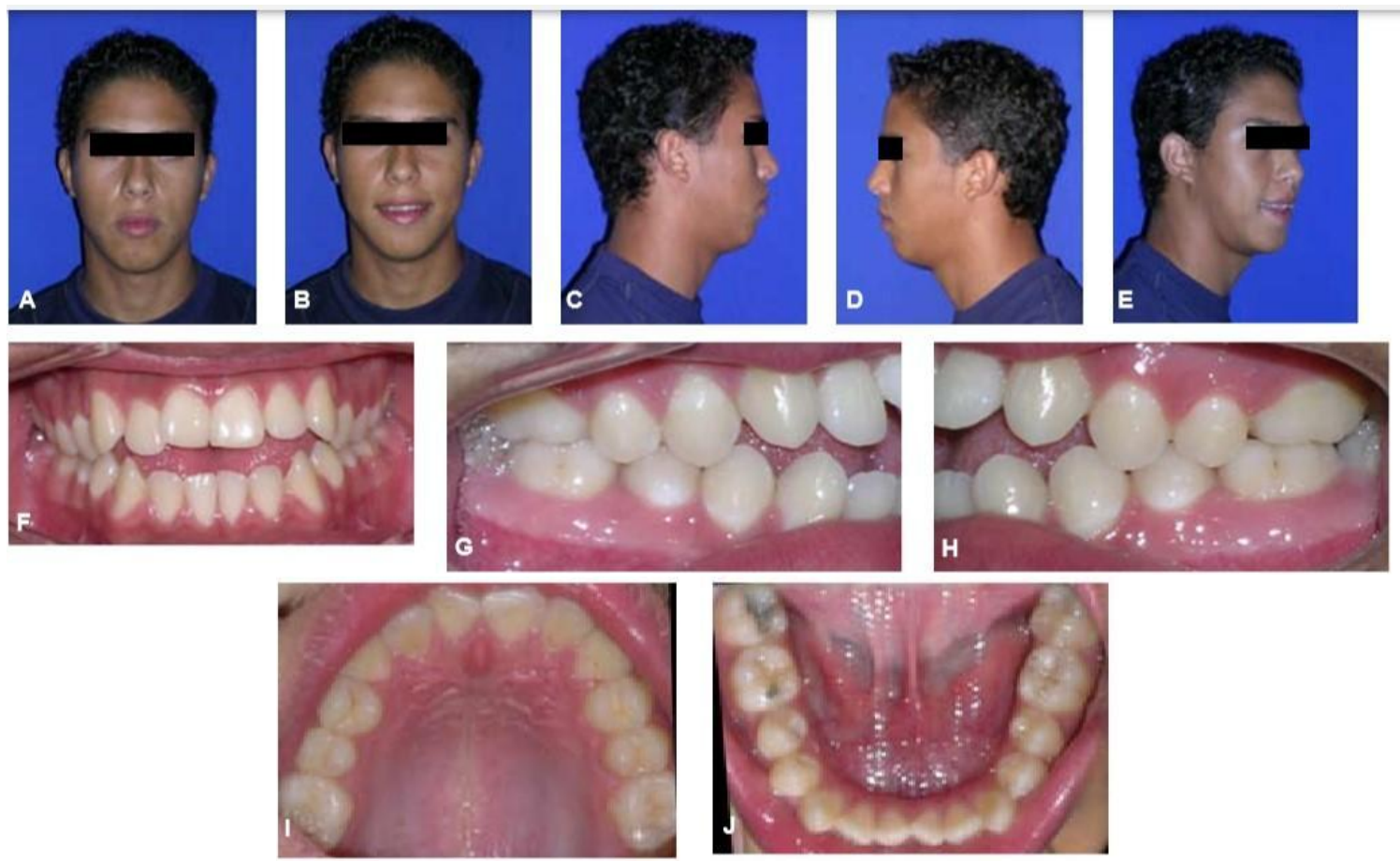

Figura 55 a-j: Fotografías iniciales. Observar compromiso de tejidos blandos y aumento de dimensión vertical debido a la patología del paciente.

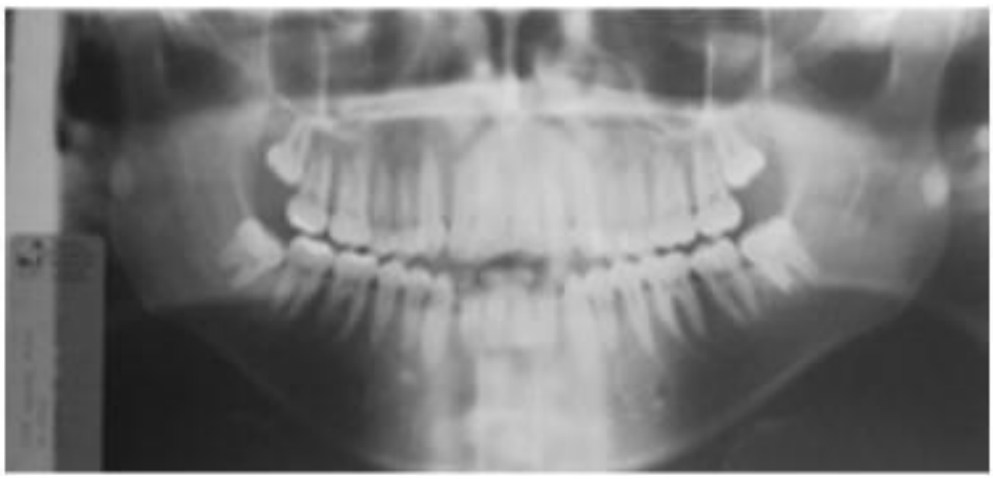

Figura 56: OPT inicial donde se observa la mordida abierta anterior de canino a canino.
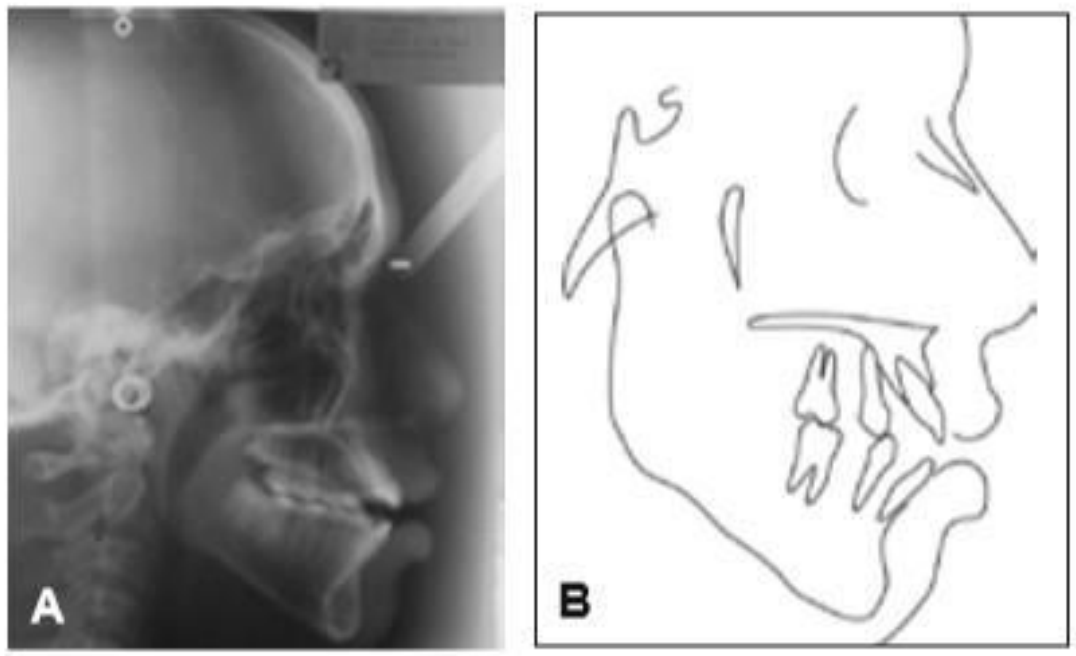

Figura 57 A y B: Telerradiografía de perfil inicial con trazado de perfil donde se observa compromiso de tejidos blandos por mordida abierta con falta de cierre oral anterior.

DOI 10.52887/RUOO/v4n2.7 RUOO 2021 Vol 4 N01 jul-dic2021 3-38 

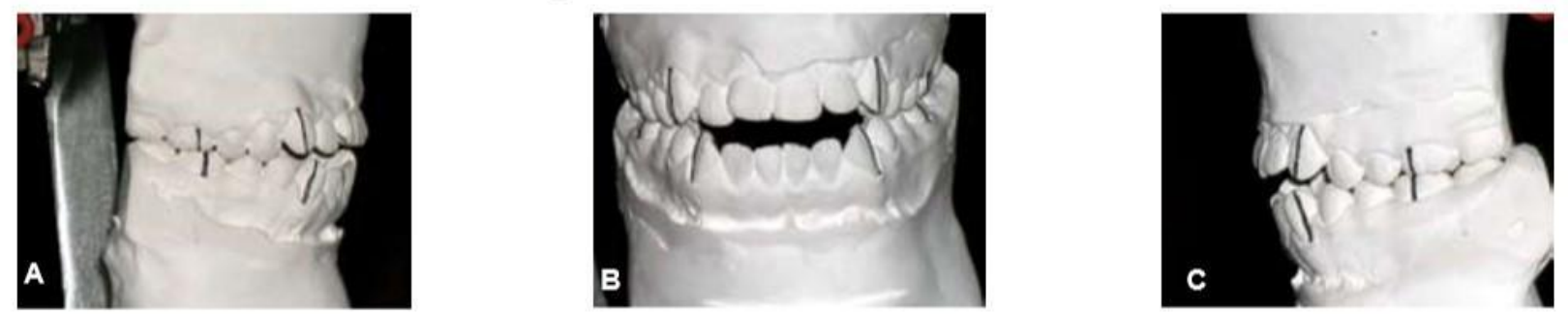

Figura 58 a b y c: Montaje inicial en articulador. Obsérvese las relaciones dentales y la magnitud de la mordida abierta anterior.

\section{EVOLUCION DEL TRATAMIENTO:}

Se instala la aparatología superior con arco NiTi Cooper 0.016 para comenzar con la etapa de alineación y nivelación (Figura 59 a, b y c).
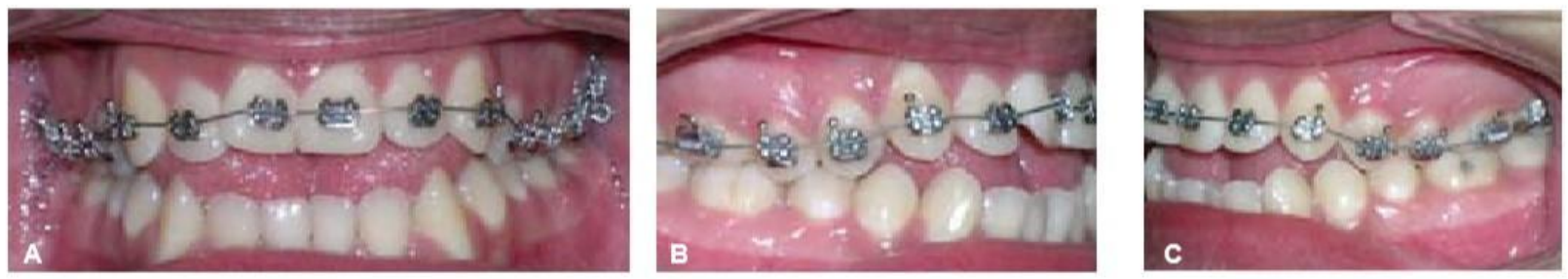

Figura 59 a, b y c: Instalación superior con arco NiTi Cooper 0.016.

Luego del primer mes ya se observa una importante disminución del apiñamiento del sector anterior (Figura 60 a y b).
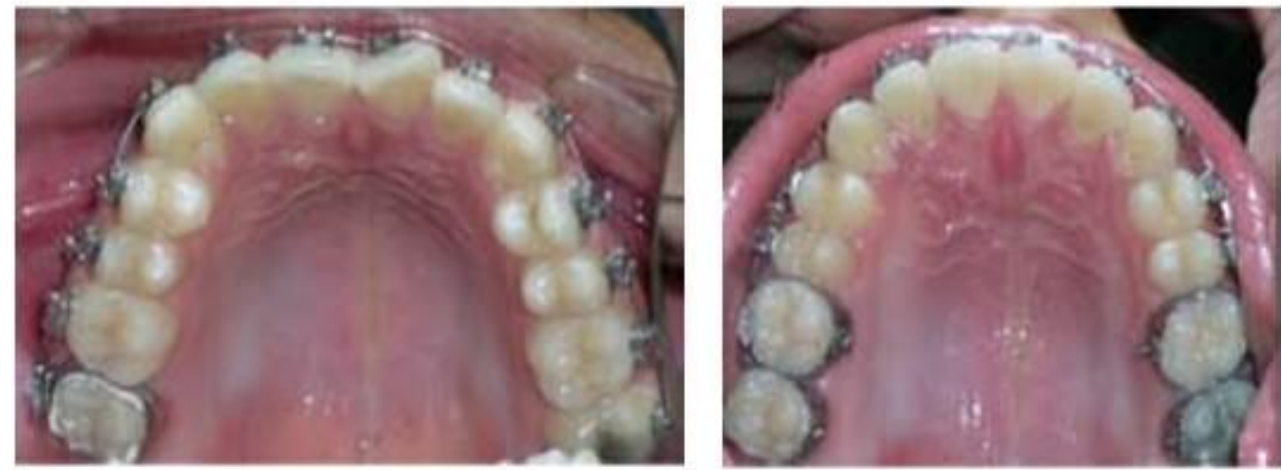

Figura 60 a: fotografía inicial y b: evolución luego del primer mes.

Luego de 7 meses de evolución el paciente ya presenta arcos NiTi 0.019x0.025 superior e inferior, mediante la secuencia de arco se consigue nivelar ambas arcadas disminuyendo la mordida abierta anterior (Figura 61 a y b) y preparar los espacios inter-radiculares para la colocación de microimplantes de manera segura, dichos microimplantes se colocan tanto por vestibular como por palatino entre 1ros y 2dos molares superiores unidos mediante módulos elásticos a la aparatología de las caras libres (Figura 62 a-e). 

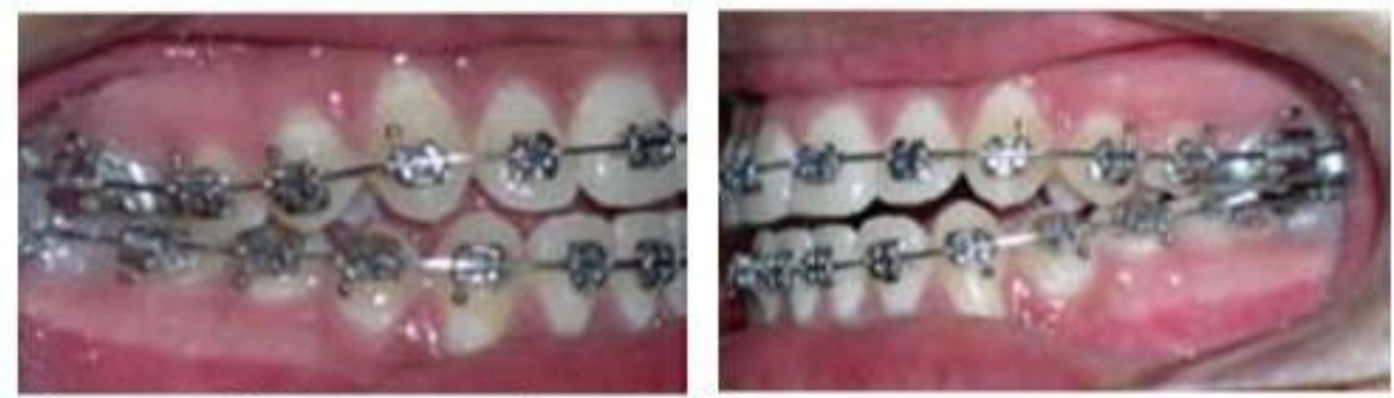

Figura 61 a y b: 7 meses de evolución, presencia de arcos NiTi 0.019x0.025 superior e inferior.
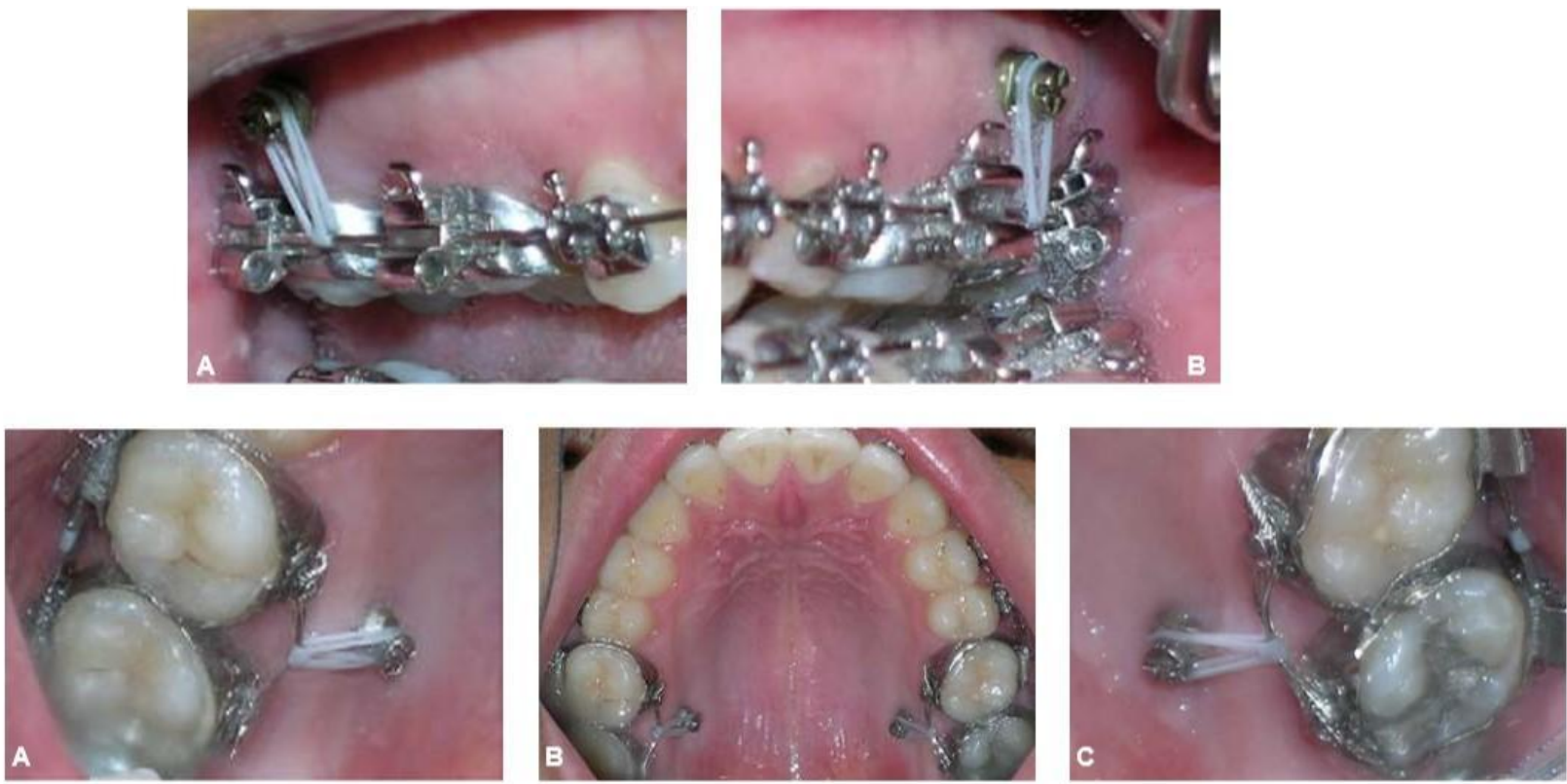

Figura $62 a, b, c, d$ y e: Colocación de microimplantes vestibulares y palatinos, conectados mediante módulos elásticos al arco vestibular (microimplantes vestibulares) y a un arco seccional colocado entre los tubos Atkinson de1ros y 2dos molares (microimplantes palatinos).

Luego de 11 meses de evolución se logran correctas relaciones de overjet y overbite anterior, se colocan arcos de finalización de acero $0.019 \times 0.025$ superior e inferior para expresar al máximo la prescripción de la aparatología logrando los tips y torques definitivos (Figura 63 a-e). 

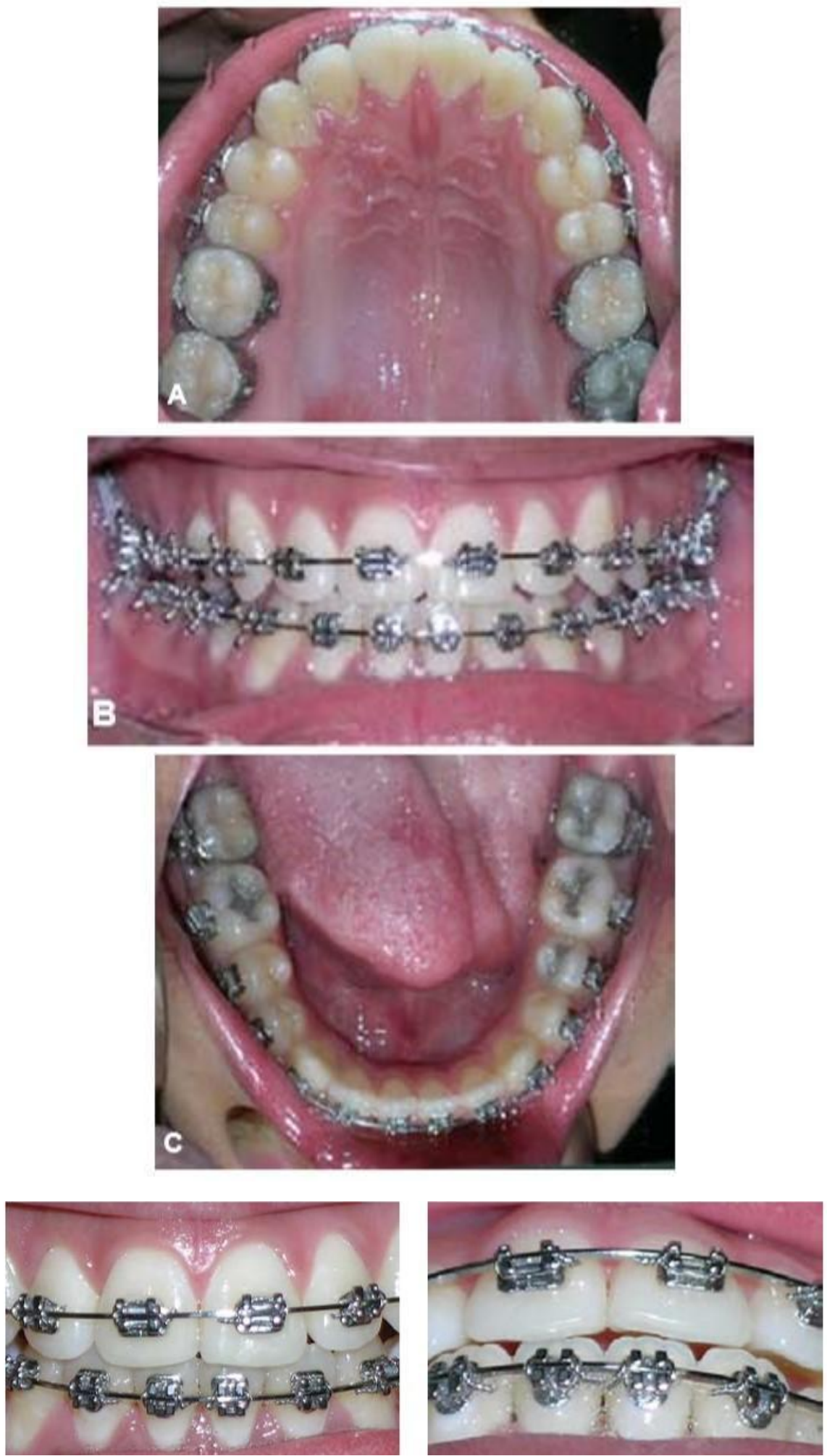

Figura 63 a, b, c, d y e: Corrección de la sobremordida. Arcos de finalización 0.019x0.025 de acero superior e inferior. Foto frontal, superior, inferior, overbite y overjet. 
En mi opinión este representa el típico caso de corrección de un problema de exceso vertical sin la necesidad de cierre de eje mediante extracciones dentarias y cierres de espacio, sino que solamante con la intrusión pósterosuperior logramos el cierre de eje necesario. En casos más severos se podrá realizar la extracción de 4 premolares (uno por cuadrante) junto con la mesialización e incluso intrusión posterior, siempre teniendo en cuenta la magnitud de cierre del eje facial requerida, así como la situación del tercio inferior de cara.

\section{CASO 3: INTRUSIÓN POSTERIOR CON ANCLAJE CIGOMÁTICO Y PALATINO. SOLUCIÓN DE UN PROBLEMA CONCRETO DENTRO DEL
TRATAMIENTO. ${ }^{7}$}

Paciente de sexo femenino de 32 años de edad realiza una consulta para realizarse la rehabilitación del sector póstero inferior derecho. En el análisis clínico de la zona motivo de consulta se observa una brecha edéntula correspondiente a las piezas 46,47 y 48 con extrusión de las piezas antagonistas (Figura 64). La paciente no presenta particularidades desde el punto de vista general ni regional, presenta un biotipo braquifacial. El tratamiento propuesto para la zona motivo de consulta es la extracción de la pieza 14 y la intrusión y mesialización mediante ortodoncia y microimplantes de las piezas 15, 16 y 17 y la posterior rehabilitación inferior con implantes.

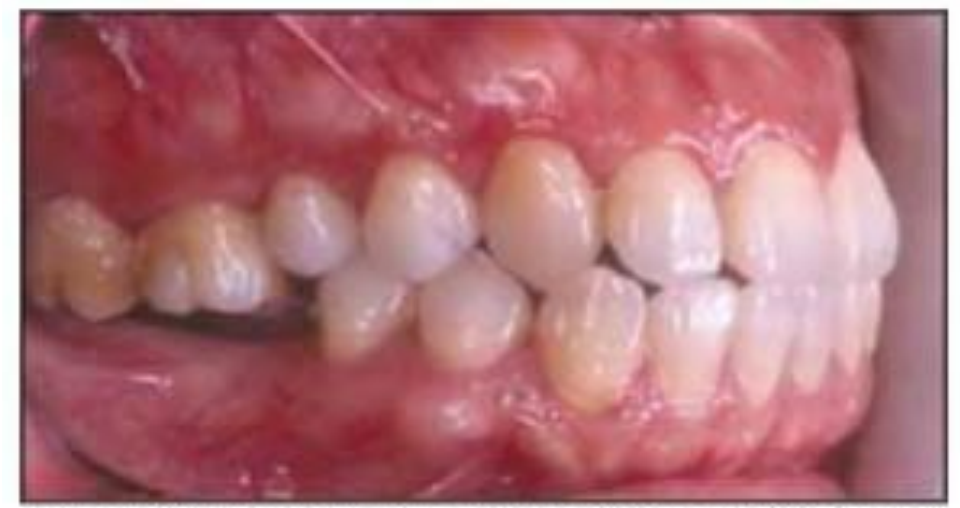

Figura 64: Fotografía intraoral inicial donde se observa la sobre erupción de las piezas 16 y 17 por falta de antagonista.

\section{EVOLUCIÓN DEL TRATAMIENTO:}

El tratamiento comienza mediante la instalación de la aparotología superior y la extracción de la pieza 14, la colocación de un microimplante infracigomático y otro a nivel del rafe palatino los cuales mediante la utilización de cadenas elásticas desde los mismos hacia la aparatología instalada en las caras libres producen la intrusión de dichas piezas. Dichas fuerzas deben ser de igual magnitud para lograr la intrusión de la/las piezas dentarias sin modificación del torque de las mismas. Se aprovechará el espacio creado por la extracción de la pieza 14 para mesializar el sector posterior (Figuras 65 y 66). 

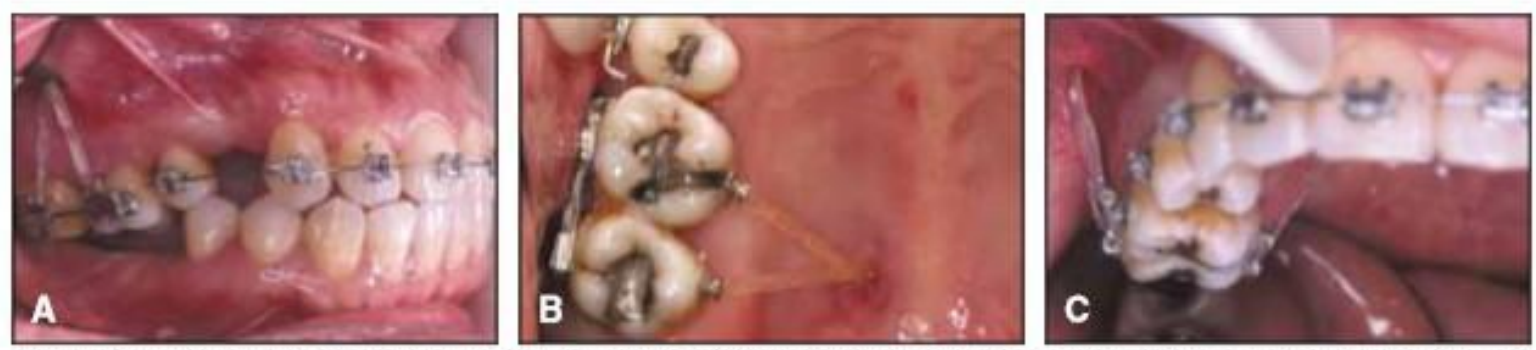

Figura 65 a, b y c: Colocación de microimplante en cresta infracigomática (fig. a). Colocación de microimplante palatino a nivel del rafe medio (fig. b). Fuerzas bilaterales intrusivas de igual magnitud mediante módulos elásticos

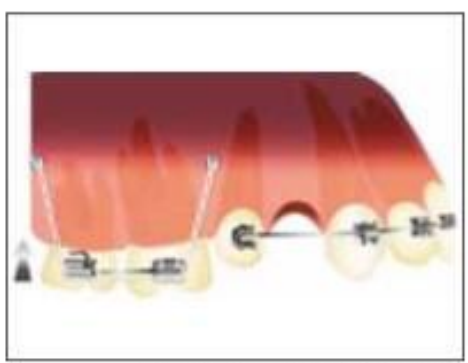
para intruir sin modificación de torque.

Figura 66: Representación gráfica de la técnica utilizada.

Luego de 5 meses observamos una mayor intrusión de la pieza 16 que de la 17 por lo que se decide modificar el sistema de fuerzas de intrusión colocando un microimplante a mesial de la pieza 16 y otro a distal de la pieza 17, de esta manera se deja de utilizar el microimplante colocado en la cresta infracigomática (Figura 67 a). Luego de 3 meses se consigue la correcta intrusión de las piezas y la nivelación del plano oclusal (Figura 67 b y c), en ese momento se coloca el implante en la zona de la pieza 47.
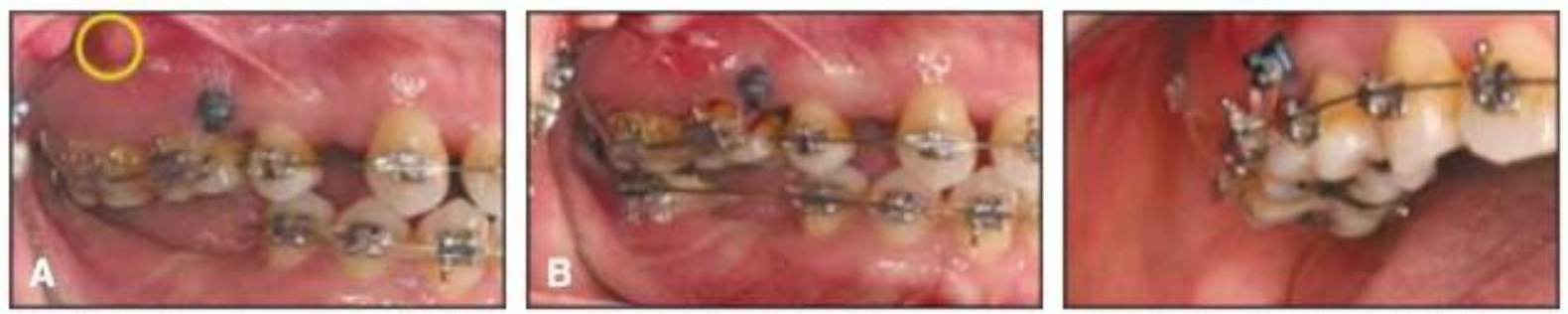

Figura 67 a, b y c: Al cabo de 5 meses se observa una correcta intrusión de la pieza 16, no así de la pieza 17. Fig A: Se colocan 2 nuevos microimplantes, uno en la tuberosidad por distal del 17 y otro interradicular entre las piezas 16 y 15 para continuar con la intrusión, dejándose de utilizar el microimplante colocado en la cresta infra-cigomática (marcado con círculo amarillo). Fig b y c: al cabo de 3 meses se consigue la correcta intrusión de la pieza 17 y se coloca un implante dental a nivel de la pieza 47 para que funcione como antagonista.

Mediante el control radiográfico con OPT en las diferentes instancias de tratamiento se observa la intrusión y mesialización de las piezas 15, 16 y 17, así como también la rehabilitación inferior implantoasistida en la zona de 47 aprovechando el espacio conseguido mediante la intrusión superior (Figura 68 $a, b$ y $c)$. 

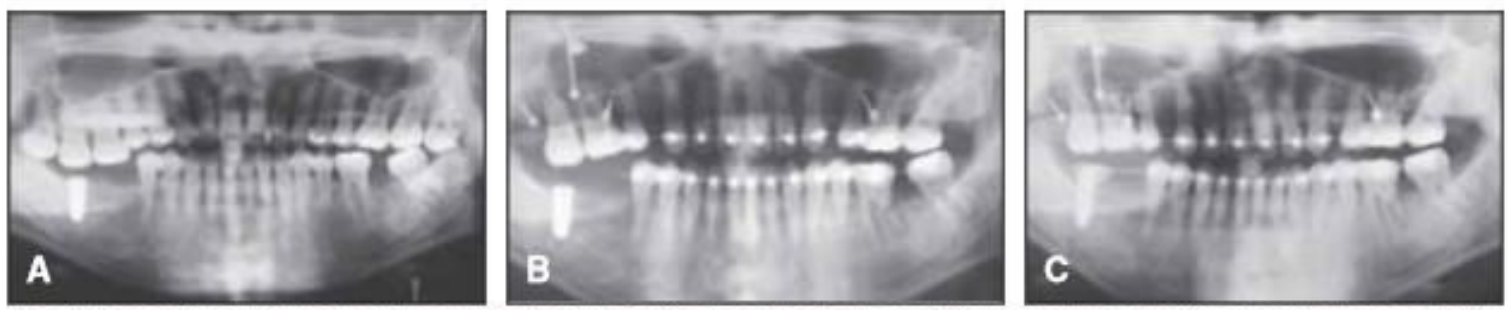

Figura 68 a, $b$ y c: Evolución del tratamiento registrado en OPT.

En mi opinión esta modalidad puede aplicarse también para casos más simples de necesidad de rehabilitación de una pieza cuando se presenta extrusión de la pieza antagonista, pudiendo incluso muchas veces no ser necesaria la instalación completa de la aparatología multibracket siempre que tengamos un buen control de las fuerzas y los torques resultantes.

\section{CONCLUSIONES}

Como respuesta a las preguntas que nos planteamos al comienzo de nuestra introducción, podemos asegurar que el cambio de paradigma generado por la llegada de los microimplantes, en cuanto a la planificación y desarrollo de nuestros casos, ha llegado para quedarse y seguir brindándonos cada día nuevas oportunidades y herramientas fundamentales para elevar la mira en lo que refiere al éxito de nuestros tratamientos.

Estos dispositivos han ido evolucionando a lo largo de la historia y se han adaptado a las diversas necesidades y exigencias terapéuticas. De esta forma contamos con una gran variedad de tamaños y formas que podemos disponer para lograr nuestros objetivos. Los microimplantes colaboran reforzando nuestro anclaje o pueden ser utilizados como único elemento de anclaje. Si bien el anclaje que brindan es el más confiable que tenemos hoy en día, siempre existe la posibilidad de pérdida de anclaje, ya sean magnitudes casi despreciables o no, por lo que el clínico deberá no sólo controlar en cada sesión el estado de ese anclaje, sino también idear sistemas que minimicen las consecuencias en caso de fallo de los microimplantes para prevenir futuros inconvenientes y poder lograr los objetivos planteados en una primera instancia. Este aspecto es fundamental cuando nuestro objetivo es cerrar espacios sin perder anclaje. Los beneficios que nos brindan se han aprovechado de diversas maneras, pudiendo solucionarse con ellos hoy en día situaciones de diversa dificultad incluso sin la necesidad de la instalación de la ortodoncia convencional multibracket. Por ejemplo, podemos tratar desde una simple extrusión molar por falta de antagonista hasta una endognacia maxilar en un paciente en crecimiento sin la necesidad de anclarnos en las piezas dentales. En lo que respecta al plano vertical, podemos corregir mordidas abiertas esqueletales de magnitudes importantes mediante la intrusión posterior, algo muy difícil de lograr previamente. A su vez, también pueden 
colaborar en la intrusión anterior en casos de sobremordidas dentarias y mordidas cubiertas esqueletales, así como también, se han comenzado a tratar casos de intrusión de una hemiarcada o una arcada completa.

Por todo lo expuesto en este artículo debemos comprender que sus características y aplicaciones son muy variadas por lo que es nuestro deber como clínicos conocer todas sus aplicaciones, sus ventajas y también sus riesgos. Así como también estudiar y conocer las características propias de cada paciente, no sólo desde el punto de vista dentario y oclusal, sino también su biotipo, el cual determinará sus características óseas, las cuales condicionarán 0 no la elección, inserción y ubicación de nuestros microimplantes, para decidir qué estrategia nos proporcionará los mejores resultados minimizando la posibilidad de producir movimientos indeseados.

\section{BIBLIOGRAFÍA}

1- Casado, A. Gaceta Dental 205. (2009) Madrid, España.

2- Sandoval Reza, C., . Generalidades de los dispositivos de anclaje temporal TAD's. Universidad Autónoma del Estado de México (2017)

3- Park, H. JuLee, Y. Density of the alveolar and basal bones of the maxilla and the mandible. (2010) Vol 133. Num 1. Pag 30-37.

4- Chena, Y. Hong-In, S. Hee-Moon, K. Biomechanical and histological comparison of self-drilling and self-tapping orthodontic microimplantsin dogs. (2008) Vol 133, Pages 44-50.

5- Clinical oral implants Research, (2014) vol 19, Pag 1091-1210.

6- Gregoret, J. y col. (2015). Tratamiento Ortodóntcico con Arco Recto. Segunda edición. Capítulo 5. Pag 249-263.

7- Nanda, R., Uribe, F. (2010). Dispositivos de Anclaje Temporal en Ortodoncia. Capítulos 1, 2, 7, 8, 16, 17. Pag 3-14, 145-167, 342-374.

8- American Journal of Orthodontics and Dentofacial Orthopedics (2006). Volume 130.

9- International Journal of Implant Dentisty Volumen (2014), article ID 424926.

10- Echarri P, Kim TW, Favero L, Kim HJ. Ortodoncia y microimplantes. Ripano, Madrid, (2014). 
11- Echarri, P. Ortodoncia Española. Corrección de la mordida profunda anterior y de la mordida abierta anterior con la técnica de arcos dobles y con brackets vestibulares y linguales. (2013).

12- Alvarez, T. McQuattie, I. Scannone, A. Revista Latinoamericana de Ortodoncia y Odontopediatría. Tratamiento alternativo en casos de Exceso Vertical del Maxilar: Uso de Microtornillos - Reporte de un Caso Clínico. (2010).

13- Calderón, A. Universidad San Francisco de Quito. Colegio de Postgrados. Microimplantes como anclaje absoluto: comparación de efectividad entre la utilización de cadena elástica y resorte cerrado de cromo-níquel en intrusión dental en perros, mediante evaluación radiográfica e histológica. (2007).

14- Echarri, P. y col. Revista oficial de la Sociedad Española de Ortodoncia, (2008). Volumen 48, Número 2.

15- Echarri, P. y col. Corrección de la mordida profunda anterior con microimplantes. (2007).

16- Aristizábal, J. y col. Revista Estomatología. Tratamiento de mordida abierta con dispositivos temporales de anclaje (dTa). (2007).

\section{Agradecimientos:}

Dr. J. Chaves - Docente titular de la clínica de Ortodoncia IUCEDDU

Dra. Ma. Victoria Calvo - Docente titular de Investigación IUCEDDU 